Article

\title{
Retrieval of Daily Reference Evapotranspiration for Croplands in South Korea Using Machine Learning with Satellite Images and Numerical Weather Prediction Data
}

\author{
Nari Kim ${ }^{1}$, Kwangjin Kim ${ }^{1}$, Soobong Lee ${ }^{2}\left(\mathbb{D}\right.$, Jaeil Cho ${ }^{3}\left(\mathbb{D}\right.$ and Yangwon Lee ${ }^{4, *(1)}$ \\ 1 Geomatics Research Institute, Pukyong National University, Busan 48513, Korea; \\ kimnari13@pukyong.ac.kr (N.K.); somakkj@pknu.ac.kr (K.K.) \\ 2 National Meteorological Satellite Center, Korea Meteorological Administration, Chungbuk 27803, Korea; \\ sblee88@korea.kr \\ 3 Department of Applied Plant Science, Chonnam National University, Gwangju 61186, Korea; \\ chojaeil@jnu.ac.kr \\ 4 Department of Spatial Information Engineering, Pukyong National University, Busan 48513, Korea \\ * Correspondence: modconfi@pknu.ac.kr
}

Received: 5 October 2020; Accepted: 4 November 2020; Published: 6 November 2020

\begin{abstract}
Evapotranspiration (ET) is an important component of the Earth's energy and water cycle via the interaction between the atmosphere and the land surface. The reference evapotranspiration $\left(\mathrm{ET}_{0}\right)$ is particularly important in the croplands because it is a convenient and reasonable method for calculating the actual evapotranspiration (AET) that represents the loss of water in the croplands through the soil evaporation and vegetation transpiration. To date, many efforts have been made to retrieve $\mathrm{ET}_{0}$ on a spatially continuous grid. In particular, the Moderate Resolution Imaging Spectroradiometer (MODIS) product is provided with a reasonable spatial resolution of $500 \mathrm{~m}$ and a temporal resolution of 8 days. However, the applicability to the local-scale variabilities due to complex and heterogeneous land surfaces in countries like South Korea is not sufficiently validated. Meanwhile, the AI approaches showed a useful functionality for the $\mathrm{ET}_{0}$ retrieval on the local scale but have rarely demonstrated a substantial product for a spatially continuous grid. This paper presented a retrieval of the daily reference evapotranspiration $\left(\mathrm{ET}_{0}\right)$ over a $500 \mathrm{~m}$ grid for croplands in South Korea using machine learning (ML) with satellite images and numerical weather prediction data. In a blind test for 2013-2019, the ML-based ET 0 model produced the accuracy statistics with a root mean square error of $1.038 \mathrm{~mm} /$ day and a correlation coefficient of 0.870 . The results of the blind test were stable irrespective of location, year, and month. This outcome is presumably because the input data of the ML-based $\mathrm{ET}_{0}$ model were suitably arranged spatially and temporally, and the optimization of the model was appropriate. We found that the relative humidity and land surface temperature were the most influential variables for the ML-based $\mathrm{ET}_{0}$ model, but the variables with lower importance were also necessary to consider the nonlinearity between the variables. Using the daily $\mathrm{ET}_{0}$ data produced over the $500 \mathrm{~m}$ grid, we conducted a case study to examine agrometeorological characteristics of the croplands in South Korea during the period when heatwave and drought events occurred. Through the experiments, the feasibility of the ML-based $\mathrm{ET}_{0}$ retrieval was validated, especially for local agrometeorological applications in regions with heterogeneous land surfaces, such as South Korea.
\end{abstract}

Keywords: agrometeorology; evapotranspiration; cropland; machine learning 


\section{Introduction}

Evapotranspiration (ET) is the transport of water vapor to the atmosphere through the evaporation from soil and canopy surfaces and the transpiration from vegetation [1]. ET is an important component of the Earth's energy and water cycles via the interaction between the atmosphere and the land surface in the form of latent heat using net radiation [2]. ET is affected by many agrometeorological variables such as radiation, temperature, humidity, wind, precipitation, and soil moisture. The amount of water transported by ET is generally greater than that by runoff in most agricultural fields [3]. Thus, the amount of irrigation water for the cropland can be determined by the cumulative amount of ET.

Potential evapotranspiration (PET) is the possible amount of ET according to climatic and meteorological conditions, assuming a sufficient supply of water [4]. Actual evapotranspiration (AET) is a substantial amount of ET, as the result of the effects of many factors such as vegetation type, the fraction of vegetation cover (FVC), phenological cycle, soil type, soil moisture, irrigation, and drainage, in addition to meteorological conditions [2]. Water management in the croplands includes the maintenance of a suitable level of soil moisture and the adjustment of irrigation water. The accurate information of AET is essential to determine the amount of irrigation water because the AET represents the loss of water in the croplands through soil evaporation and vegetation transpiration. The in situ AET is usually obtained from the eddy covariance [5] that can be measured by the energy and water exchanges between the land surface and the atmosphere on a micrometeorological tower [6]. It is the most scientifically reliable system for the in situ measurement of AET, but the installation and operation of the eddy covariance instruments on the micrometeorological tower require high costs and many efforts [7].

For the sake of convenience, the AET can be calculated by multiplying a crop coefficient $\left(\mathrm{K}_{\mathrm{c}}\right)$ by the reference evapotranspiration $\left(\mathrm{ET}_{0}\right)$ defined as the $\mathrm{ET}$ of well-irrigated hypothetical grassland under a specific meteorological condition [2]. Hence, the $\mathrm{K}_{\mathrm{c}}$ is expressed as the ratio of AET to $\mathrm{ET}_{0}$. The $\mathrm{ET}_{0}$ can have a similar physical quantity as PET, but is in a more agricultural context, assuming the calculation of AET using the $\mathrm{K}_{\mathrm{c}}$ [8]. The $\mathrm{ET}_{0}$ for a given point can be easily derived from the Food and Agriculture Organization (FAO) version of the Penman-Monteith (PM) equation only using meteorological parameters [3], without the hydrological and physiological factors such as soil moisture and stomatal resistance. While the meteorological input data for the PM equation is usually obtainable, the physiological and phenological properties of the crops are hard to quantify in detail. So, the $\mathrm{K}_{\mathrm{c}}$ can be a useful method for the estimation of AET in the croplands. Under considerations of the possible use for the AET estimation, an efficient calculation of $\mathrm{ET}_{0}$ using meteorological data will be of help for many agrometeorological studies.

Despite the usefulness of $\mathrm{K}_{\mathrm{c}}$ in the AET estimation, it is usually confined to a specific point because some of the input data are only obtainable from in situ point observations. However, individual point observations cannot fully represent spatially continuous areas, although ET can vary spatially according to the meteorological and cropland variables. To date, many efforts have been made to retrieve PET, $\mathrm{ET}_{0}$, and AET over a continuous grid. Most of them tried to expand the point-based calculation of PET, $\mathrm{ET}_{0}$, and AET to a continuous grid using satellite images and gridded meteorological data with the linkage to the PM equation [9-17] or the Priestley-Taylor (PT) equation with the empirically derived coefficients fitted for the study areas [18-28]. They also introduced additional factors to the retrieval process for a more realistic simulation of $\mathrm{ET}_{0}$ or AET, such as soil structure [29], terrain effect [9], stomatal conductance $[10,13]$, diurnal temperature difference $[24,30]$, and vegetation greenness $[12,24]$. Additionally, some previous studies estimated $\mathrm{ET}_{0}$ or $\mathrm{AET}$ using satellite-derived vegetation index and net radiation data with a statistical model like linear regression [30,31]. Recently, artificial intelligence (AI) approaches using the techniques like neural network $(\mathrm{NN})$ or machine learning $(\mathrm{ML})$ have tried to take account of the nonlinearity between ET and the variables for meteorological and land surface conditions, showing a possibility for the retrieval of the gridded $\mathrm{ET}_{0}$ or AET [32-35]. Because the PM and PT equations and the AI techniques are already in a stable status, the construction of a reasonable 
database for the meteorological and land surface conditions is one of the critical points for the effective retrieval of gridded $\mathrm{ET}_{0}$ and $\mathrm{AET}$.

Currently, the operative gridded ET products are available from the Climatic Research Unit (CRU), TerraClimate, and Moderate Resolution Imaging Spectroradiometer (MODIS). The $\mathrm{ET}_{0}$ products by the CRU and the TerraClimate are the monthly reanalysis data suitable for long-term climate researches. So, they cannot support examining daily or weekly changes for the applications in agriculture, hydrology, and meteorology. On the other hand, the MODIS product (MOD16A2GF) has a reasonable spatial resolution of $500 \mathrm{~m}$ and a temporal resolution of 8 days. However, the applicability to the local-scale variabilities due to complex and heterogeneous land surfaces in countries like South Korea is not sufficiently validated. Meanwhile, the $\mathrm{AI}$ approaches have rarely demonstrated a substantial product for the daily gridded $\mathrm{ET}_{0}$ on the local scale, although they showed a useful functionality for the $\mathrm{ET}_{0}$ retrieval on the local scale.

In this paper, we present ML-based modeling of daily local-scale $\mathrm{ET}_{0}$ that can be used for estimating the crop AET, with the consideration of the complexity and nonlinearity between $\mathrm{ET}_{0}$ and input variables, and thereby produce a daily $500 \mathrm{~m} \mathrm{ET}_{0}$ in the croplands of South Korea. Vegetation data from MODIS, precipitation data from Global Precipitation Measurement (GPM), and meteorological data from Unified Model (UM) Local Data Assimilation and Prediction System (LDAPS) were used as input features for the ML-based daily $\mathrm{ET}_{0}$ model. The in situ point-based $\mathrm{ET}_{0}$ data taken by the Korea Meteorological Administration (KMA) were used for training and blind testing of our model for the period between March and November 2013-2019. We also present the accuracy statistics followed by the characteristics of meteorology, hydrology, and vegetation in the croplands of South Korea in recent years using the daily $\mathrm{ET}_{0}$ retrieved over the $500 \mathrm{~m}$ grid.

\section{Data}

\subsection{Overview}

For the retrieval of the daily $\mathrm{ET}_{0}$ over the $500 \mathrm{~m}$ grid in South Korea, we used the following input variables: normalized difference vegetation index (NDVI), leaf area index (LAI), and fraction of photosynthetically active radiation (FPAR) from MODIS; standardized precipitation index for three months (SPI3) from GPM; air temperature, land surface temperature, soil temperature, relative humidity, and wind speed from UM LDAPS. The ML models were built using these input data and the in situ $\mathrm{ET}_{0}$ data taken from KMA (Figure 1). The database was constructed for the period between March and November of 2013-2019, excluding the winter season when evaporation from soil and transpiration from vegetation are insignificant. For the data processing, we employed the MODIS Reprojection Tool (MRT) and the R programming with Geospatial Data Abstraction Library (GDAL). Additionally, R programming with the h2o library was conducted for the optimization of the ML model and the creation of the $\mathrm{ET}_{0}$ data over the $500 \mathrm{~m}$ grid.

\subsection{In Situ Reference Evapotranspiration Data}

One effective method for quantifying the $\mathrm{ET}_{0}$ is to use the pan evaporation $\left(\mathrm{E}_{\mathrm{p}}\right)$ and the pan coefficient $\left(\mathrm{K}_{\mathrm{p}}\right)$. The $\mathrm{E}_{\mathrm{p}}$ is the in situ observation using an evaporation pan, and the $\mathrm{K}_{\mathrm{p}}$ is defined as the ratio of $\mathrm{ET}_{0}$ to $\mathrm{E}_{\mathrm{p}}$. Given an $\mathrm{E}_{\mathrm{p}}$ and a $\mathrm{K}_{\mathrm{p}}$, one can directly obtain the $\mathrm{ET}_{0}$ even without meteorological observations. In the case of $\mathrm{KMA}$, the $\mathrm{K}_{\mathrm{p}}$ was prepared in advance by fitting the linear relationship between the observed $\mathrm{E}_{\mathrm{p}}$ and the $\mathrm{ET}_{0}$ derived by the PM equation using in situ meteorological data. Through this procedure, KMA provides the $\mathrm{ET}_{0}$ by the multiplication of $\mathrm{E}_{\mathrm{p}}$ and $\mathrm{K}_{\mathrm{p}}$ for the nine points in South Korea (Figure 2). They are part of the Automated Surface Observing System (ASOS) stations on the croplands having the equipment of evaporation pan. The ASOS meteorological data and the $\mathrm{E}_{\mathrm{p}}$ 
data of the nine stations have almost no missing values during 2013-2019. We aggregated the KMA $\mathrm{ET}_{0}$ data on a daily basis for the calibration/validation for the ML-based daily $\mathrm{ET}_{0}$ model.

$$
\mathrm{ET}_{0}=\frac{0.408 \Delta\left(R_{n}-G\right)+\gamma \frac{900}{T+273.15} u_{2}\left(e_{s}-e_{a}\right)}{\Delta+\gamma\left(1+0.34 u_{2}\right)}
$$

where $\Delta$ is the slope of the vapor pressure curve; $R_{n}$ is the net radiation; $G$ is the soil heat flux; $\gamma$ is the psychrometric constant; $T$ is the near-surface air temperature; $u_{2}$ is the two-dimensional wind speed; $e_{S}$ is the saturation vapor pressure; $e_{a}$ is the actual vapor pressure. The constant 0.408 is for the conversion of the unit from $\mathrm{MJ} / \mathrm{m}^{2} /$ day to $\mathrm{mm} /$ day, and the constant 273.15 is for the temperature conversion from Kelvin to Celsius. The constants 900 and 0.34 are the empirical coefficients for the daily $\mathrm{ET}_{0}$ proposed by $\mathrm{FAO}[1]$.

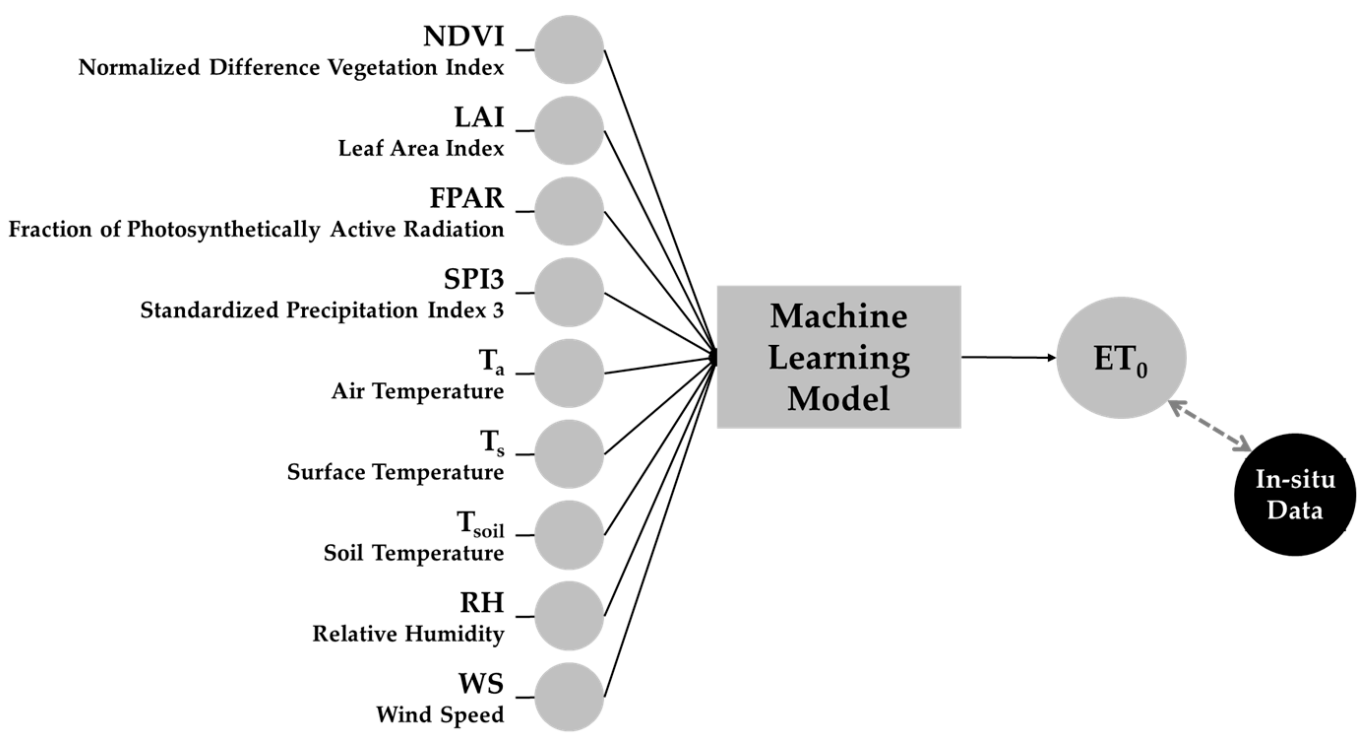

Figure 1. Input variables for the machine learning (ML) model to retrieve the gridded reference evapotranspiration $\left(\mathrm{ET}_{0}\right)$ in the croplands of South Korea, with the in situ point data from Korea Meteorology Administration (KMA).

\subsection{Satellite Images}

The MODIS instrument is a satellite sensor operated by the National Aeronautics and Space Administration (NASA) for Earth environmental monitoring onboard the Terra and Aqua satellites with a sun-synchronous orbit. The satellites pass over a specific location at the same local time every day. Terra crosses the equator from north to south (descending path) at approximately 10:30 AM local time. Aqua crosses the equator from south to north (ascending path) at approximately 1:30 PM local time. We obtained the NDVI, LAI, and FPAR products as the indicators of vegetation vitality, biomass, and gross primary production (GPP), from the Aqua MODIS.

NDVI is a commonly used vegetation index that represents the vitality and greenness of vegetation. We used the MYD13C2 monthly product that has a resolution of $0.05^{\circ}$, instead of the MYD13A1 16-day product with a $500 \mathrm{~m}$ resolution because the 16 -day $500 \mathrm{~m}$ product has many missing pixels due to clouds, particularly in summer. On the other hand, the monthly $0.05^{\circ}$ product has almost no missing pixels through the spatial and temporal smoothing. In general, vegetation greenness changes gradually in the form of a cosine curve over a year, so we converted the monthly product to daily values using the cubic spline method. The LAI, which is calculated using a crop-specific growth coefficient and maximum GPP, can be used as a proxy of the leaf biomass. FPAR is the portion of photosynthetically active radiation absorbed by green vegetation. We obtained LAI and FPAR from the MCD15A2H 8-day 
product with a resolution of $500 \mathrm{~m}$, based on a combination of Terra and Aqua products, by choosing the best pixel available from all acquisitions of both sensors within the 8-day period.

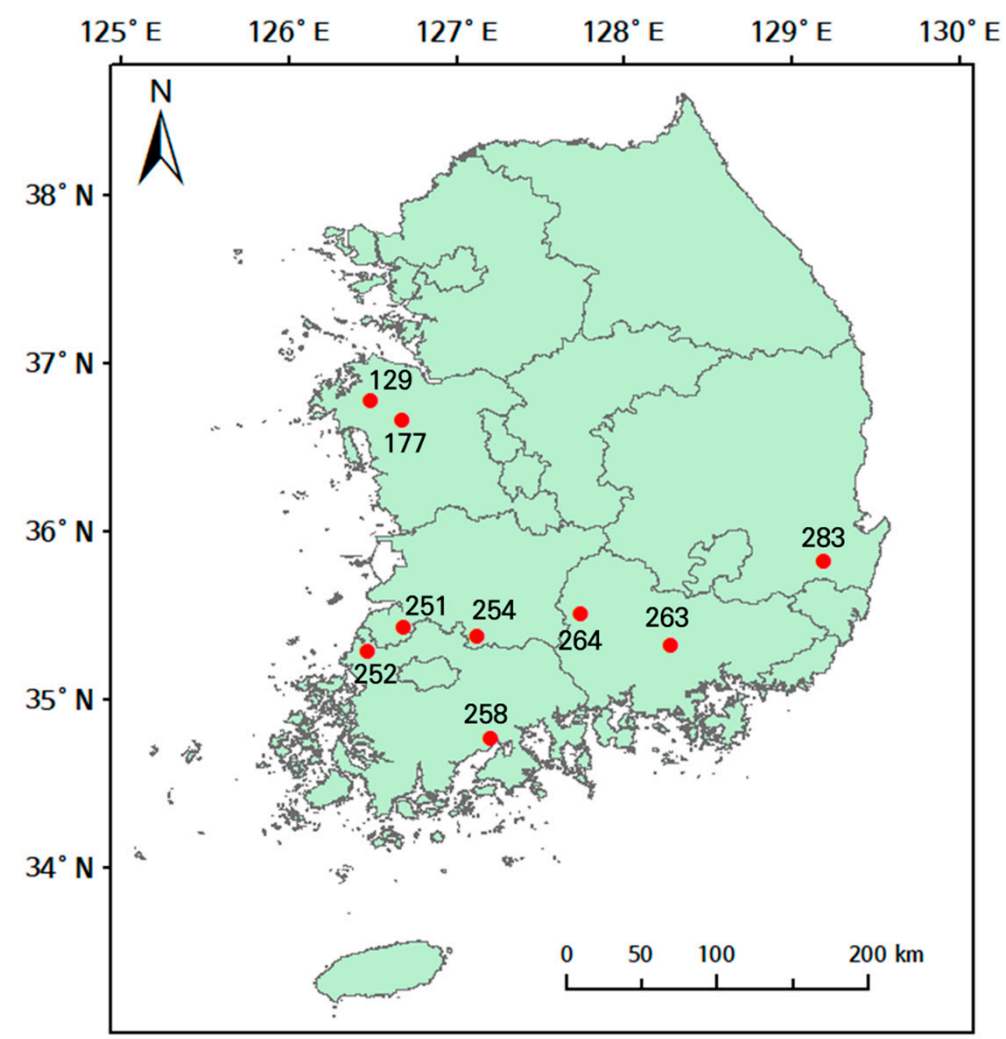

Figure 2. Measurement locations for the reference evapotranspiration $\left(\mathrm{ET}_{0}\right)$ by the Korea Meteorological Administration (KMA). The digits around the red points are the station identification number.

To extract croplands in South Korea, we used the MODIS land-cover type product (MCD12Q1), which was created by the supervised classification using the reflectance of multiple spectral bands, with an annual update over the $500 \mathrm{~m}$ grid [36]. According to the classification criteria released by the International Geosphere-Biosphere Programme (IGBP), we extracted the pixels associated with croplands, including type 12 (croplands) and type 14 (cropland/natural vegetation mosaic).

The Global Precipitation Measurement (GPM) mission comprises an international satellite network that provides the next-generation global observations of rain and snow to elucidate Earth's water and energy cycles [37]. We used the TRMM_3B42_Daily version 7 product, which provides better rainfall estimates than previous versions, with significantly lower bias over complex topography [38]. Precipitation is the supply of water to the land surface, which can be infiltrated and evaporated by soil or transpired by vegetation. Because cumulative precipitation is generally more closely associated with $\mathrm{ET}_{0}$ than daily precipitation, we used SPI3, which is calculated from the z-score of the empirical cumulative distribution function (ECDF) of 3-month accumulated precipitation.

$$
\mathrm{z}=\frac{x_{i}-\mu}{\sigma}
$$

where $x_{i}$ is the ECDF of $i$-th day; $\mu$ is the mean of the entire ECDF; $\sigma$ is the standard deviation of the ECDF. 


\subsection{Numerical Weather Prediction Data}

The LDAPS is the numerical weather prediction model operated by the KMA that is a locally optimized version of the UM from the MetOffice of the United Kingdom (UK). The UM LDAPS provides a 3-hourly weather forecast over a $1.5 \mathrm{~km}$ grid using three-dimensional variational data assimilation (3DVAR) with optimized parameterizations for the physical processes such as radiation, boundary layer, convection, and the land-atmosphere interactions. The land surface variables are produced by the UK MetOffice Surface Exchange Scheme (MOSES), which computes the momentum, thermal energy exchange, water flux, and CO2 flux, based on the land-atmosphere interaction scheme in the land surface model (LSM). We extracted the variables air temperature, land surface temperature, soil temperature at $10 \mathrm{~cm}$ depth, relative humidity, and wind speed at noon local time every day from 2013 to 2019.

\section{Methods}

\subsection{Spatial and Temporal Matchup}

The 9 variables collected for the retrieval of $\mathrm{ET}_{0}$ have different spatial and temporal resolutions, as summarized in Table 1 . For use as input features for the ML-based $\mathrm{ET}_{0}$ model, the variables should be spatially and temporally co-located to construct a matchup database. The MODIS LAI and FPAR data use a sinusoidal projection; the GPM precipitation data use a geographic projection; the LDAPS meteorological variables use a Lambert Conformal Conic (LCC) projection. In addition, the datasets have various spatial resolutions. We converted all datasets into the geographic projections based on latitude and longitude with a $500 \mathrm{~m}$ (15 arc-second) grid to construct a matchup database for the various data sources. The transformation of the coordinate reference system (CRS) was performed using the MRT and GDAL. The adjustment of spatial resolution was carried out using the bilinear interpolation that is based on the distance between the center points of each pixel. For temporal resolutions, we adjusted all datasets to an interval of 1 day. MODIS NDVI was converted through cubic spline interpolation, assuming the gradual change over a year. MODIS LAI and FPAR data from the 8-day composite were rearranged to daily values using the nearest neighbor method under the assumption that they do not usually change within 8 days. LDAPS meteorological variables such as air temperature, land surface temperature, soil temperature, relative humidity, and wind speed at noon were treated as representative values for the day.

Table 1. Spatial and temporal resolutions of the data used as input features for the ML-based $\mathrm{ET}_{0}$ model.

\begin{tabular}{cccc}
\hline Data Source & Variable & Spatial Resolution & Temporal Resolution \\
\hline MODIS ${ }^{1}$ & NDVI $^{2}$ & $0.05^{\circ}$ & 1 month \\
& LAI $^{3}$ & $500 \mathrm{~m}$ & 8 days \\
& FPAR $^{4}$ & $500 \mathrm{~m}$ & 8 days \\
\hline GPM $^{5}$ & SPI3 $^{6}$ & $0.25^{\circ}$ & 1 day \\
\hline LDAPS $^{7}$ & Air temperature & $1.5 \mathrm{~km}$ & $3 \mathrm{~h}$ \\
& Land surface temperature & $1.5 \mathrm{~km}$ & $3 \mathrm{~h}$ \\
& Soil temperature & $1.5 \mathrm{~km}$ & $3 \mathrm{~h}$ \\
& Relative humidity & $1.5 \mathrm{~km}$ & $3 \mathrm{~h}$ \\
Wind speed & $1.5 \mathrm{~km}$ & $3 \mathrm{~h}$ \\
\hline${ }^{1}$ Moderate Resolution Imaging Spectroradiometer; ${ }^{2}$ normalized difference vegetation index; ${ }^{3}$ leaf area index; \\
fraction of photosynthetically active radiation; ${ }^{5}$ Global Precipitation Measurement; ${ }^{6}$ standardized precipitation \\
index (for three-month accumulated precipitation); ${ }^{7}$ Local Data Assimilation and Prediction System.
\end{tabular}

\subsection{Random Forest and Its Extensions}

RF is an ensemble machine learning model that conducts classification and regression using the bootstrap and bagging methods [39]. The RF generates many decision trees with different input features 
through random sampling of training data. Resampling is conducted via bootstrapping if necessary, to achieve a suitable distribution of training samples. As an extension of the RF model, the gradient boosting machine (GBM) and the extreme gradient boosting (XGBoost) adopt a boosting method instead of bagging. The boosting considers the prediction performance of each sample during the iteration of training. The XGBoost uses more regularized trees than the GBM for the adjustment of the weighting scheme [40]. We used the three ensemble machine learning methods (RF, GBM, and XGBoost) and compared the test results to select the most suitable model. The number of decision trees (ntree) and the number of variables for splitting the tree branches (mtry) are the critical hyperparameters for the optimization of the three models [41]. We set the ntree parameter to 100 (Figure 3), and the mtry parameter to the number of input features divided by three, based on optimization experiments.

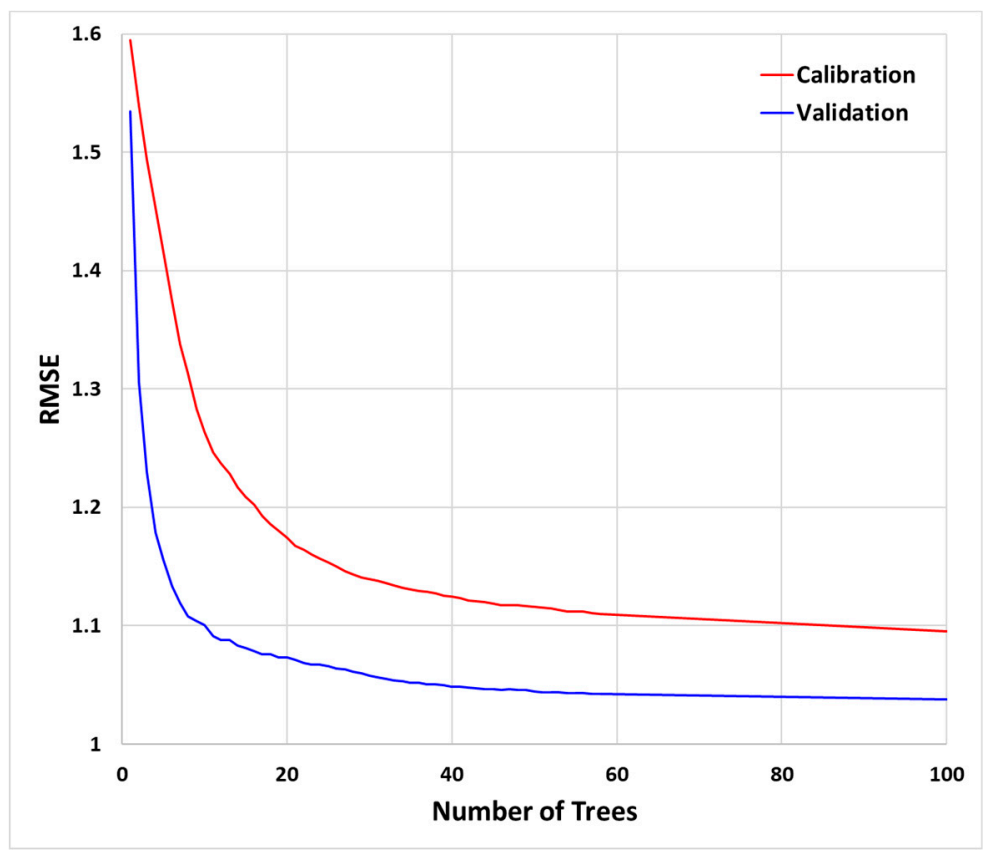

Figure 3. The changes in the root mean square error (RMSE) according to the number of trees in the calibration/validation process of the random forest (RF) modeling. The RMSEs almost converged when the number of trees is around 100.

\subsection{Training and Blind Test}

Statistical models are usually optimized through a calibration/validation process for parameter adjustment using a training dataset extracted from the whole database. Data that were not included in the training dataset were used for blind testing of the optimized model. We constructed 16,125 matchups for the ML-based daily $\mathrm{ET}_{0}$ modeling in the croplands of South Korea for the period between March and November of 2013-2019. We first divided the whole matchups into 80\% (12,941 records) for training and 20\% (3184 records) for the blind test. This sampling was performed with consideration of the monthly distribution of data so that the ML-based $\mathrm{ET}_{0}$ model could learn from the temporally representative dataset. Using the training dataset, we first conducted a 10-fold calibration/validation to optimize the ML-based $\mathrm{ET}_{0}$ model (Figure 4). Then, we conducted a blind test using the remaining data and derived the accuracy statistics, including mean bias error (MBE), mean absolute error (MAE), root mean square error (RMSE), and correlation coefficient (CC). 


\section{Calibration Validation}

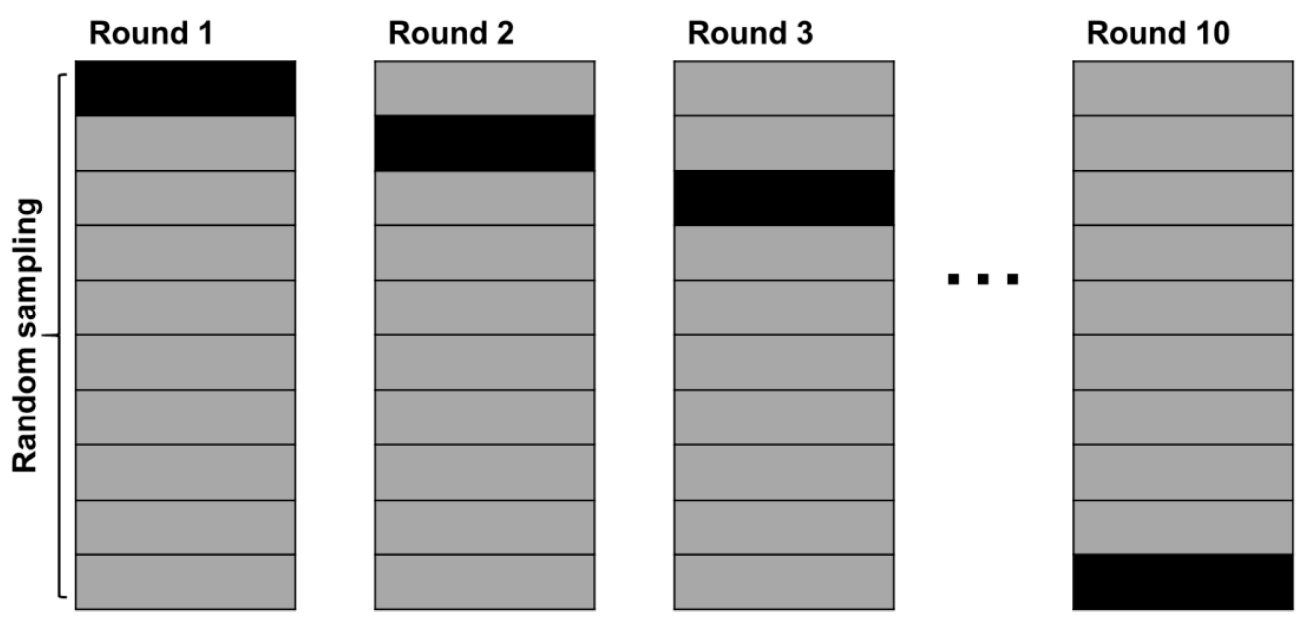

Figure 4. Conceptual diagram of 10-fold calibration/validation with random sampling [42].

\subsection{Comparison with Operative Product}

A comparison with an operative product was also conducted to more objectively evaluate our ML-based $\mathrm{ET}_{0}$ retrievals. The MODIS PET product (MOD16A2GF) is a year-end gap-filled 8-day composite with a $500 \mathrm{~m}$ resolution. The retrieval algorithm was based on the PM equation and used daily meteorological reanalysis data along with MODIS products such as vegetation, albedo, and land cover [43].

\section{Result and Discussion}

\subsection{Retrieval of Daily Reference Evapotranspiration}

The optimization of the three ML models (RF, GBM, and XGBoost) was conducted through the training process, followed by the blind test for the optimized models. The accuracy statistics of the three models were very similar, although the RF showed slightly better performance (Table 2). We chose the RF model because it is a commonly used machine learning model of which maintenance and rebuilding are more convenient.

Table 2. Accuracy comparison of the three machine-learning (ML) models.

\begin{tabular}{ccccc}
\hline Model & MBE & MAE & RMSE & CC $^{\mathbf{1}}$ \\
\hline Random forest (RF) & 0.007 & 0.790 & 1.038 & 0.870 \\
Gradient boosting machine (GBM) & 0.010 & 0.820 & 1.068 & 0.862 \\
Extreme gradient boosting (XGBoost) & 0.000 & 0.786 & 1.039 & 0.869 \\
\hline \multicolumn{2}{c}{${ }^{1} p$-value $<0.001}$.
\end{tabular}

Figure 5 shows the accuracy statistics of the blind test of the RF model. The MBE was $0.007 \mathrm{~mm} /$ day, including unbiased predictions without over- or under-estimation. The MAE was $0.790 \mathrm{~mm} /$ day, the RMSE was $1.038 \mathrm{~mm} /$ day, and the CC was 0.870 , indicating quite a strong accordance with the KMA in situ data. A scatterplot also shows that the test retrieval for the 3,184 cases was successful, with few deviations from the 1:1 line. 


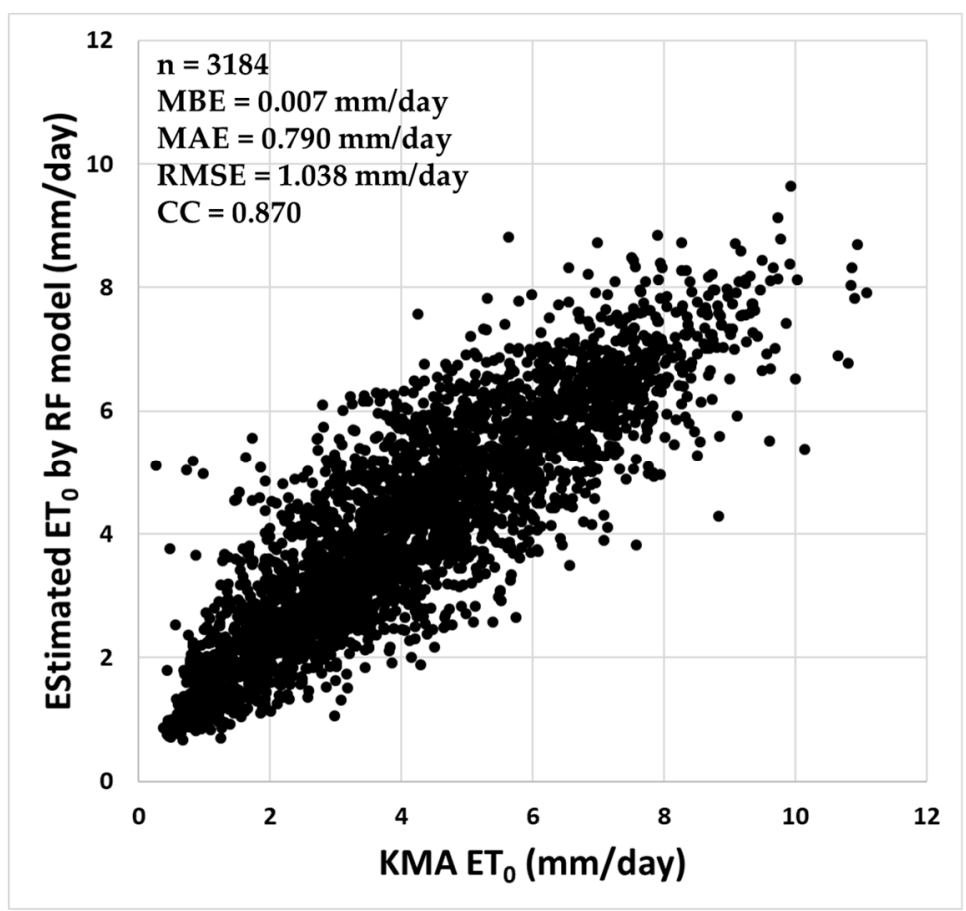

Figure 5. Scatterplot for the Korea Meteorological Administration (KMA) in situ daily $\mathrm{ET}_{0}$ vs. estimated daily $\mathrm{ET}_{0}$ in the blind test of the RF model in the croplands of South Korea, 2013-2019, with the accuracy statistics in terms of the mean bias error (MBE), mean absolute error (MAE), root mean square error (RMSE), and correlation coefficient (CC).

The importance of 9 variables was evaluated based on permutation feature importance (PFI) [41] (Table 3). Relative humidity, land surface temperature, and air temperature accounted for about $70 \%$ of the importance of all variables. The transport of water vapor from the soil and vegetation to the atmosphere is mainly controlled by the heat transfer between the land surface and the atmosphere [44]. Relative humidity $(\mathrm{PFI}=33.2 \%)$ is directly associated with the vapor pressure deficit $(\mathrm{VPD})\left(e_{s}-e_{a}\right)$ in the PM equation, which represents the capacity of the diffusion of water vapor to the atmosphere. Under the conditions of sufficient soil moisture, a high VPD and low relative humidity result in high evapotranspiration (Figure 6a). Although the degree of stomatal opening, which is associated with the transpiration rate, can be decreased under extremely dry conditions of very high VPD, the plant transpiration is generally increased by the high evaporative capacity [45]. The land surface temperature $(\mathrm{PFI}=25.1 \%)$ and the air temperature $(\mathrm{PFI}=11.9 \%)$ can influence the relative humidity. Indeed, the land surface temperature had a positive relationship with $\mathrm{ET}_{0}$ (Figure $6 \mathrm{~b}$ ), as mentioned in the previous studies [46]. The evaporation can increase if high thermal energy is available to convert the liquid water to water vapor under a sufficient supply of water. 
Table 3. Importance of the input variables of the ML-based daily $\mathrm{ET}_{0}$ model in the croplands of South Korea, 2013-2019.

\begin{tabular}{ccc}
\hline Rank & Variable & PFI (\%) $\mathbf{1}^{\mathbf{1}}$ \\
\hline 1 & Relative humidity & 33.170 \\
2 & Land surface temperature & 25.052 \\
3 & Air temperature & 11.932 \\
4 & Soil temperature & 8.480 \\
5 & SPI3 & 6.106 \\
6 & NDVI & 4.487 \\
7 & Wind speed & 4.243 \\
8 & LAI & 3.516 \\
9 & FPAR & 3.014 \\
\hline Sum & & 100
\end{tabular}

${ }^{1}$ Permutation feature importance (PFI) is defined to be the decrease in the model score when the values of a single feature are shuffled in the matchup database, indicating how much the model depends on the feature [41].

(a)

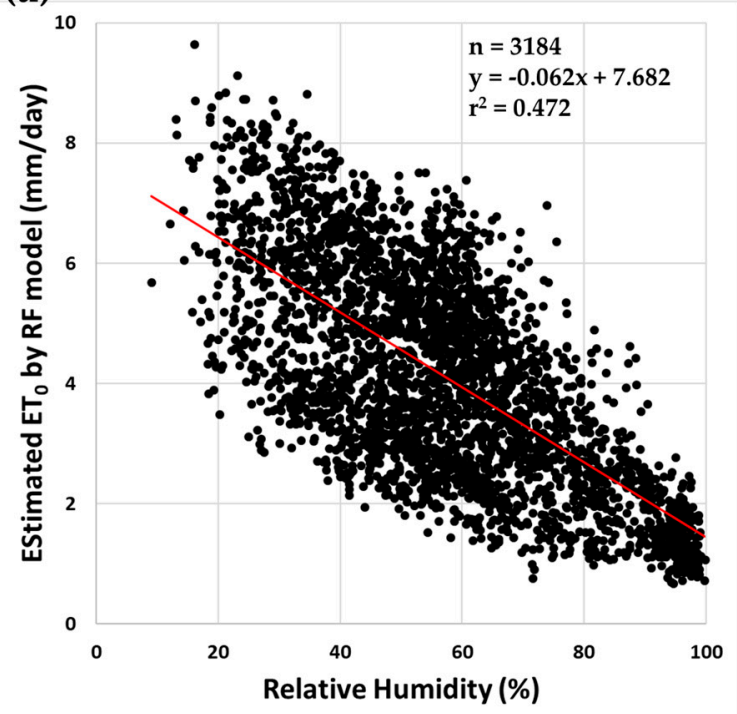

(b)

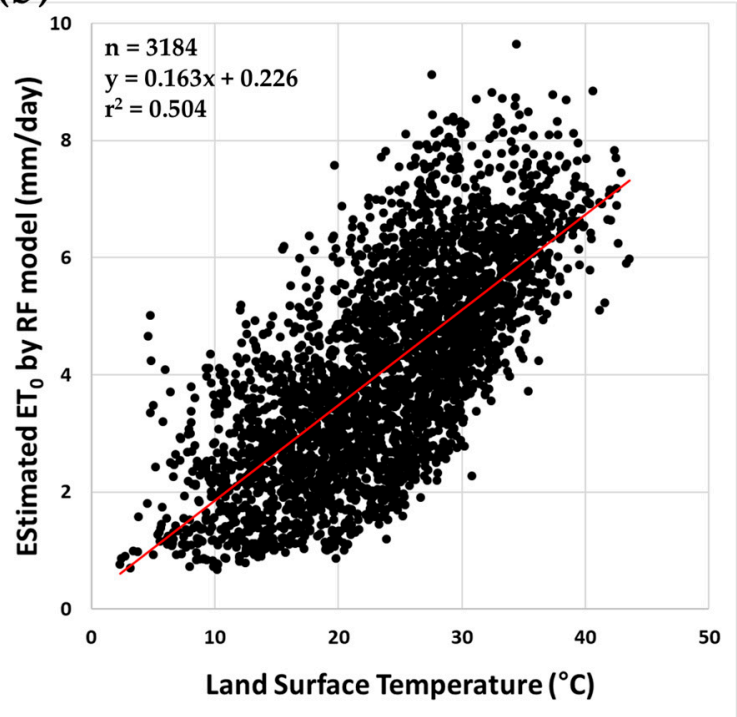

Figure 6. Relationships of the relative humidity vs. $\mathrm{ET}_{0}(\mathbf{a})$ and the land surface temperature vs. $\mathrm{ET}_{0}(\mathbf{b})$.

$\mathrm{ET}_{0}$ is not directly controlled by rainfall or vegetation phenology, according to the definition of $\mathrm{ET}_{0}$. However, the high-priority variables of the $\mathrm{ET}_{0}$ model can have direct or indirect relationships with the other variables, such as rainfall and vegetation (NDVI, LAI, and FPAR). Hence, the variables with lower importance should not be considered unnecessary for the AI modeling of $\mathrm{ET}_{0}$ to cope with the nonlinearity between the variables. Figure 7 shows that the estimation errors were not significantly influenced by wind speed. Further, the errors were decreased when the wind was strong because the aerodynamic resistance, which is generally governed by wind speed, has less fluctuation against the wind speed under strong winds [47]. 


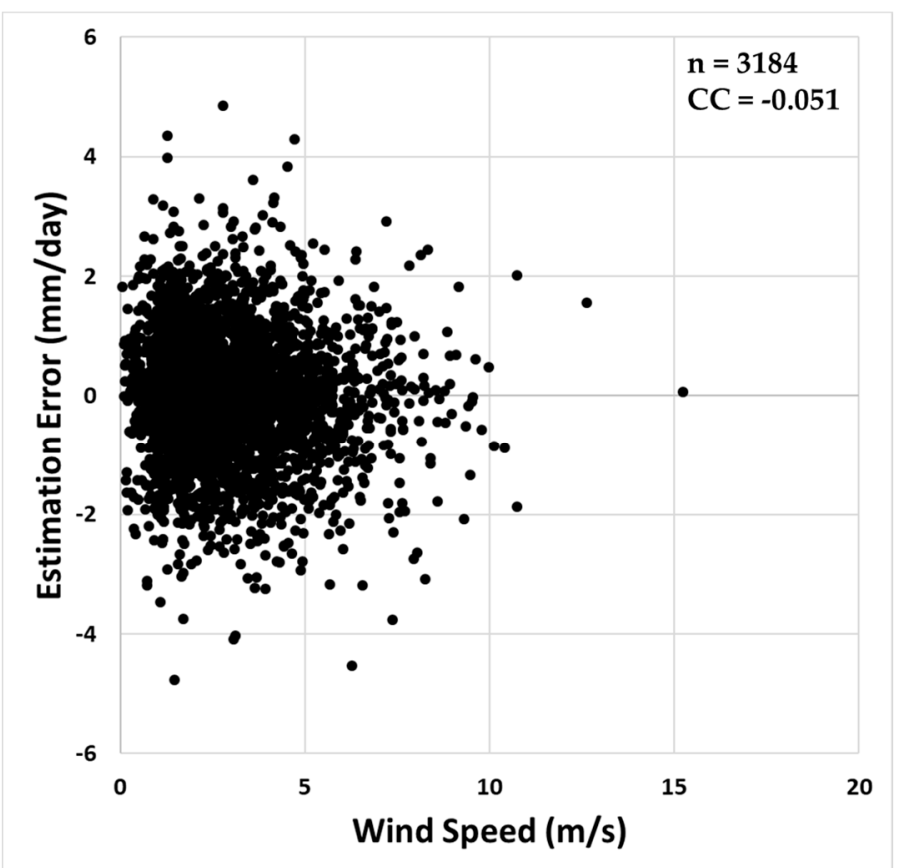

Figure 7. Relationships between wind speed and the estimation error of $\mathrm{ET}_{0}$. No correlation was found between them.

\subsection{Spatial and Temporal Characteristics of the Accuracy Statistics}

For a more detailed examination of the daily $\mathrm{ET}_{0}$ retrieval, the accuracy statistics were summarized according to location, year, and month. Table 4 shows the accuracy associated with the nine stations in the croplands of South Korea used for in situ measurements. Station 177 was associated with the highest accuracy, with the MAE of $0.703 \mathrm{~mm} /$ day, the RMSE of $0.955 \mathrm{~mm} /$ day, and the CC of 0.896 , whereas station 254 results were the least accurate, with the MAE of $0.878 \mathrm{~mm} /$ day, the RMSE of $1.144 \mathrm{~mm} /$ day, and the CC of 0.833 . The overall accuracy of the daily $\mathrm{ET}_{0}$ was similar among the nine stations because the $\mathrm{ET}_{0}$ is not affected by the local condition of the land surfaces. Figure 8 shows scatterplots for the nine stations, in which data trends are generally in accordance with the 1:1 line.

Table 4. Accuracy statistics of the nine stations in the croplands in South Korea, 2013-2019.

\begin{tabular}{ccccc}
\hline Station No. & MBE & MAE & RMSE & CC $^{\mathbf{1}}$ \\
\hline 129 & 0.381 & 0.795 & 1.016 & 0.857 \\
177 & -0.037 & 0.703 & 0.955 & 0.896 \\
251 & 0.158 & 0.734 & 0.951 & 0.900 \\
252 & -0.150 & 0.795 & 1.053 & 0.862 \\
254 & -0.072 & 0.878 & 1.144 & 0.833 \\
258 & 0.018 & 0.765 & 1.001 & 0.870 \\
263 & 0.015 & 0.838 & 1.098 & 0.850 \\
264 & -0.234 & 0.809 & 1.058 & 0.884 \\
283 & -0.124 & 0.761 & 1.029 & 0.898 \\
\hline \multicolumn{5}{c}{$1 p$-value $<0.001}$. \\
\end{tabular}

The temporal characteristics of the accuracy statistics according to year were also examined. The MAE for each year ranged between 0.745 and $0.834 \mathrm{~mm} /$ day; RMSE ranged from 0.996 to $1.092 \mathrm{~mm} /$ day; the CC ranged between 0.852 and 0.893 . No significant differences among years were found, indicating that the accuracy statistics were stable across years (Table 5; Figure 9) because the input features from the satellite images and numerical reanalysis product well reflect the meteorological and land surface conditions according to the time-series of the seven years. 
129

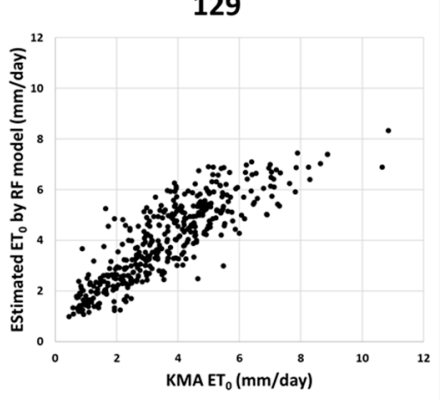

252

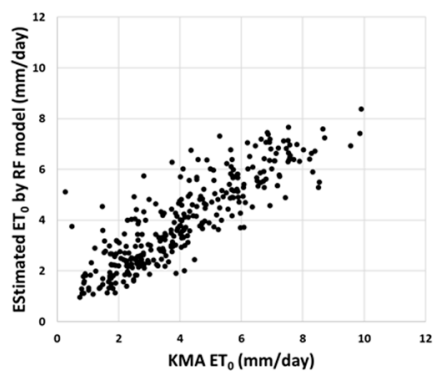

263

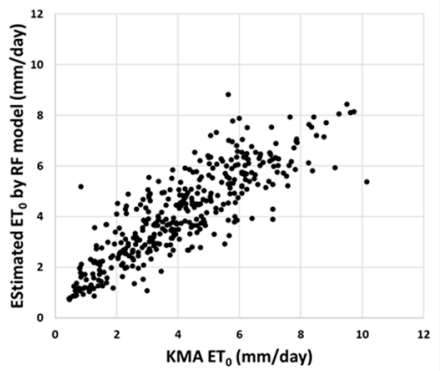

177

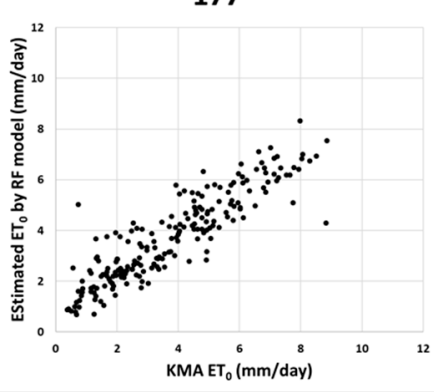

254

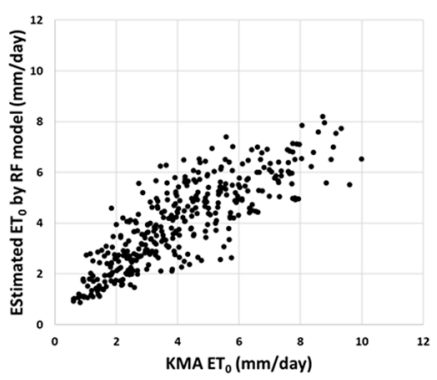

264

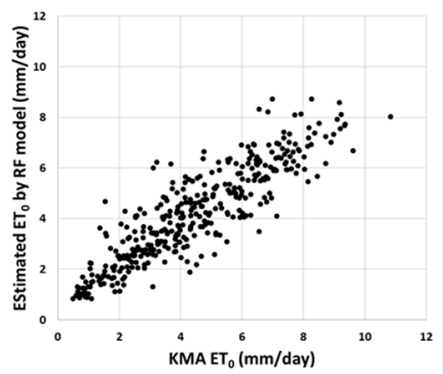

251

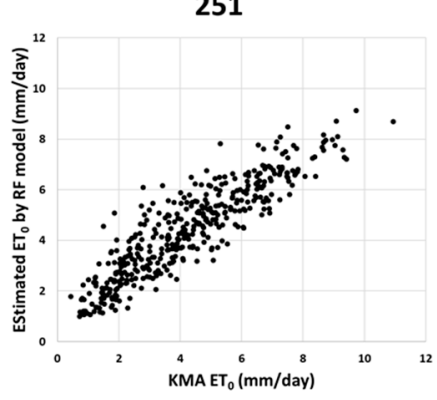

258

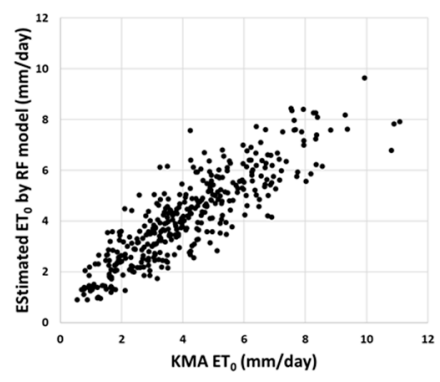

283

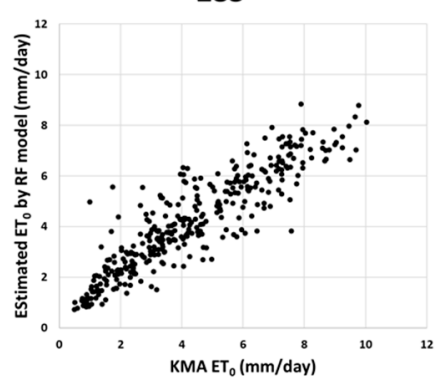

Figure 8. Scatterplots for the observed vs. estimated daily $\mathrm{ET}_{0}$ in the blind test of the ML model for the nine stations in the croplands of South Korea, 2013-2019.

Table 5. Accuracy statistics of the ML-based $\mathrm{ET}_{0}$ model in the croplands in South Korea, according to year.

\begin{tabular}{ccccc}
\hline Year & MBE & MAE & RMSE & CC $^{\mathbf{1}}$ \\
\hline 2013 & 0.143 & 0.789 & 1.021 & 0.870 \\
2014 & -0.092 & 0.790 & 1.015 & 0.868 \\
2015 & -0.017 & 0.834 & 1.092 & 0.893 \\
2016 & 0.025 & 0.784 & 1.050 & 0.852 \\
2017 & -0.034 & 0.813 & 1.071 & 0.856 \\
2018 & -0.004 & 0.778 & 0.996 & 0.875 \\
2019 & 0.030 & 0.745 & 1.015 & 0.873 \\
\hline
\end{tabular}

${ }^{1} p$-value $<0.001$.

We investigated the seasonal characteristics of the accuracy statistics according to the month between March and November. The MAE and the RMSE were somewhat lower in colder months (September to March) than in warmer months (April to August). Because soil evaporation and vegetation transpiration levels are low in the cold season, the amount of ET is relatively small (Table 6), and accordingly, the errors are also small (Table 7). However, this result does not mean that the accuracy was better in the cold season than in the warm season. We also calculated the normalized root mean square error (NRMSE), which is the RMSE divided by the mean of the observation values to 
account for seasonal variations in the value ranges. Table 7 shows the accuracy statistics by month, including the NRMSE. In contrast to the RMSE, the NRMSE values were similar across all months, indicating that the $\mathrm{ET}_{0}$ retrievals were stable irrespective of the month (Figure 10). The accuracy was lowest in August, presumably because the quality of satellite data is lowered in the cloudier season.
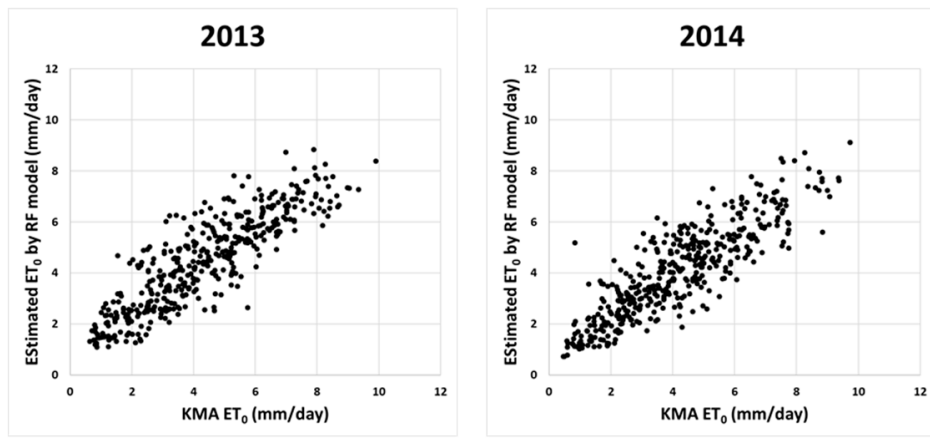

2015

2016
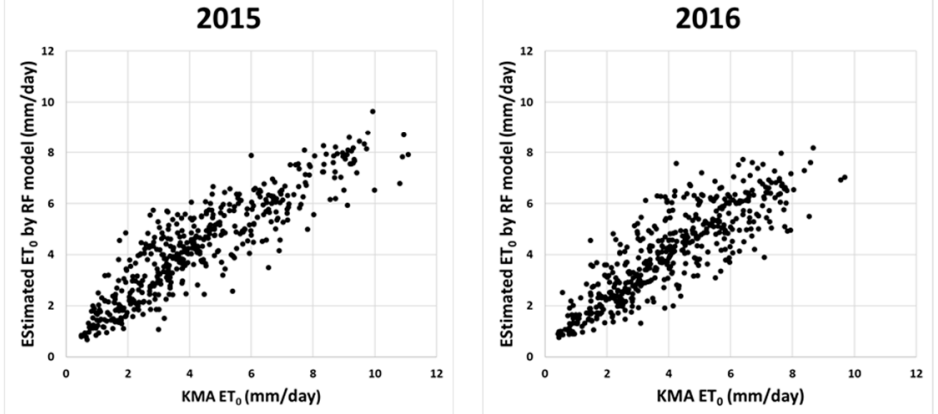

2017

2018
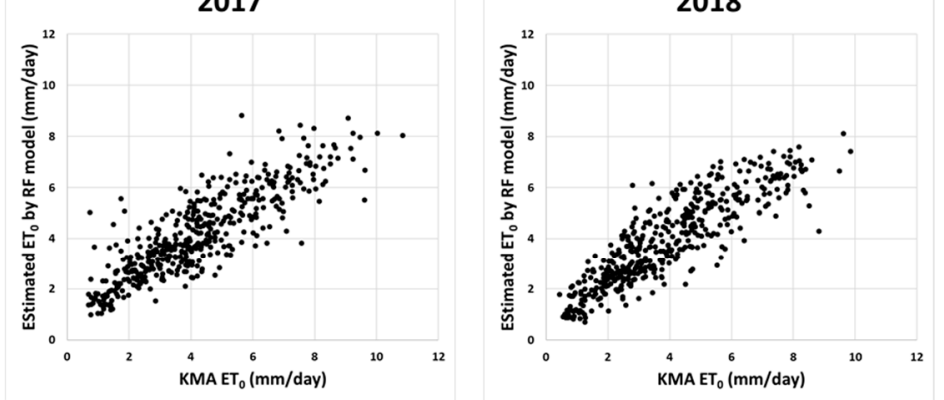

2019

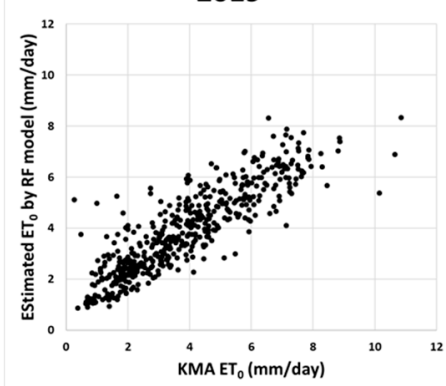

Figure 9. Scatterplots for the observed vs. estimated daily $\mathrm{ET}_{0}$ in the blind test of the ML model in the croplands of South Korea, according to year. 
Table 6. Comparison of observed vs. estimated daily $\mathrm{ET}_{0}$ in the croplands in South Korea, with their min, max, and mean.

\begin{tabular}{ccccccc}
\hline & \multicolumn{3}{c}{ Observed ET } & \multicolumn{3}{c}{ Estimated ET } \\
\cline { 2 - 7 } Month & $\begin{array}{c}\text { Min } \\
\text { (mm/day) }\end{array}$ & $\begin{array}{c}\text { Max } \\
\text { (mm/day) }\end{array}$ & $\begin{array}{c}\text { Mean } \\
\text { (mm/day) }\end{array}$ & $\begin{array}{c}\text { Min } \\
\text { (mm/day) }\end{array}$ & $\begin{array}{c}\text { Max } \\
\text { (mm/day) }\end{array}$ & $\begin{array}{c}\text { Mean } \\
\text { (mm/day) }\end{array}$ \\
\hline March & 0.494 & 8.555 & 3.572 & 0.840 & 7.582 & 3.600 \\
April & 0.599 & 9.621 & 4.493 & 0.826 & 8.395 & 4.479 \\
May & 0.771 & 11.087 & 5.933 & 1.001 & 9.640 & 5.674 \\
June & 0.698 & 10.145 & 5.124 & 1.299 & 8.437 & 5.013 \\
July & 0.570 & 10.852 & 4.492 & 1.001 & 8.325 & 4.442 \\
August & 0.476 & 9.243 & 4.576 & 1.022 & 7.827 & 4.749 \\
September & 0.264 & 8.183 & 3.786 & 0.868 & 6.881 & 3.907 \\
October & 0.584 & 6.679 & 3.109 & 1.000 & 6.517 & 3.208 \\
November & 0.384 & 5.615 & 2.257 & 0.673 & 4.934 & 2.351 \\
\hline
\end{tabular}

Table 7. Accuracy statistics of the ML-based $\mathrm{ET}_{0}$ model in the croplands in South Korea, according to month.

\begin{tabular}{cccccc}
\hline Month & MBE $(\mathbf{m m} /$ day) & MAE (mm/day) & RMSE (mm/day) & NRMSE $^{\mathbf{1}}$ & CC $^{\mathbf{2}}$ \\
\hline March & 0.027 & 0.701 & 0.892 & 0.250 & 0.815 \\
April & -0.015 & 0.875 & 1.150 & 0.256 & 0.851 \\
May & -0.260 & 0.969 & 1.234 & 0.208 & 0.853 \\
June & -0.111 & 0.934 & 1.180 & 0.230 & 0.825 \\
July & -0.051 & 0.876 & 1.103 & 0.245 & 0.851 \\
August & 0.174 & 0.853 & 1.241 & 0.271 & 0.770 \\
September & 0.121 & 0.808 & 1.058 & 0.279 & 0.774 \\
October & 0.100 & 0.603 & 0.771 & 0.248 & 0.790 \\
November & 0.094 & 0.444 & 0.561 & 0.249 & 0.808 \\
\hline
\end{tabular}

${ }^{1}$ Normalized root mean square error, which is the RMSE divided by the mean observation. ${ }^{2} p$-value $<0.001$.

A comparison with the operative MODIS PET product (MOD16A2GF) was conducted for a more objective assessment of our $\mathrm{ET}_{0}$ retrievals because the PET can be considered the same physical quantity as $\mathrm{ET}_{0}$. Since MOD16A2GF comprises 8-day composite data, we aggregated the daily $\mathrm{ET}_{0}$ and in situ data into 8-day bins for these comparisons. Table 8 shows the accuracy statistics of the ML model and MODIS product against the in situ data collected during 2013-2019. Both 8-day composite datasets led to good model performance due to the effects of temporal smoothing. However, the results of the ML model were much better than those from the MODIS product for croplands in South Korea (Figure 11). The RMSE of our retrievals was 73\% smaller than that of MODIS PET ((1.142-0.304)/1.142), and the ML model produced an almost perfect CC of 0.982 . This difference in performance is because our ML model was locally optimized for South Korea, whereas the MODIS PET algorithm was not specifically designed for South Korea. This finding also indicates that the arrangement of the input features for the ML model was spatially and temporally appropriate. The 8-day LAI/FPAR and the daily NDVI created through time-series interpolation appeared suitable for the estimation of daily $\mathrm{ET}_{0}$, as described previously $[48,49]$. 

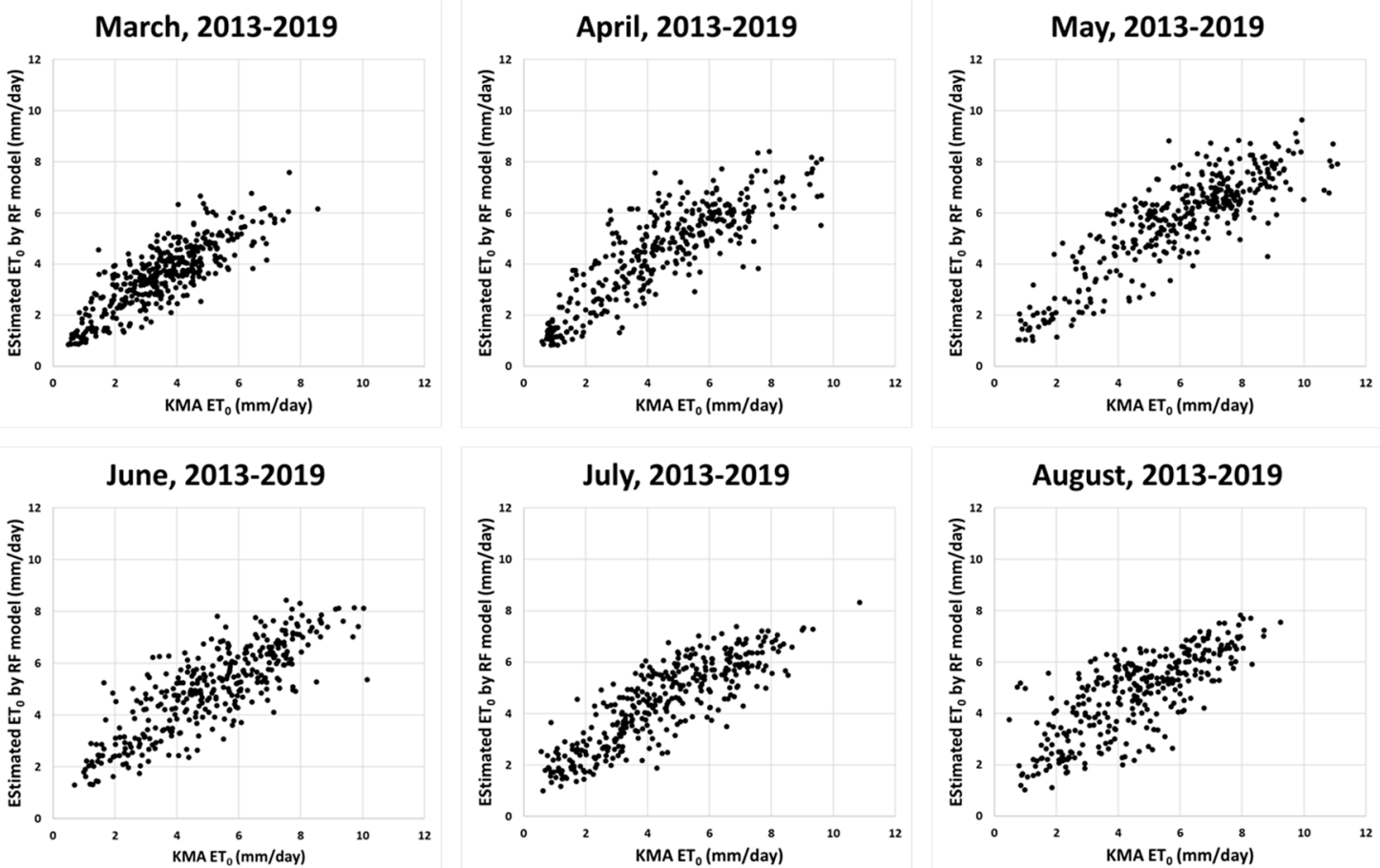

September, 2013-2019

October, 2013-2019
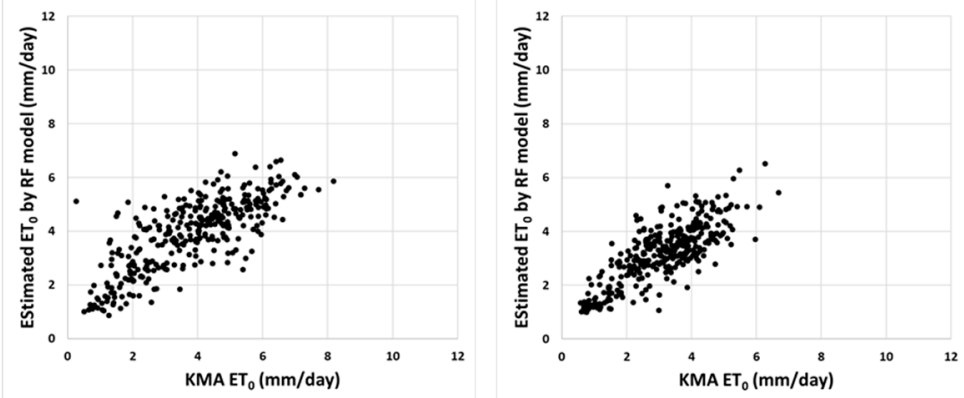

November, 2013-2019

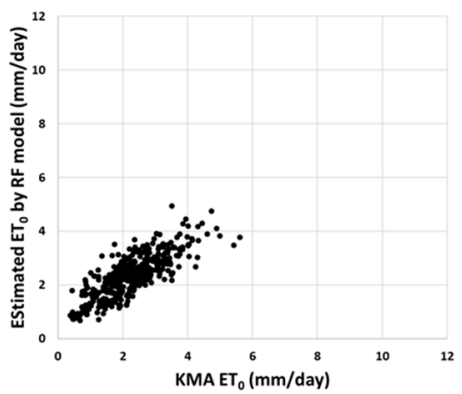

Figure 10. Scatterplots for the observed vs. estimated daily $\mathrm{ET}_{0}$ in the blind test of the ML model in the croplands of South Korea, according to month.

Table 8. Comparison of the accuracy statistics of the ML model and Moderate Resolution Imaging and Spectroradiometer (MODIS) product using 8-day composite data for croplands in South Korea for the 2013-2019 period.

\begin{tabular}{|c|c|c|c|c|c|}
\hline Retrieval & MBE (mm/day) & MAE (mm/day) & RMSE (mm/day) & $\mathrm{CC}^{1}$ & n \\
\hline This study & -0.001 & 0.234 & 0.304 & 0.982 & 1883 \\
\hline MODIS & 0.337 & 0.867 & 1.142 & 0.769 & 1883 \\
\hline
\end{tabular}



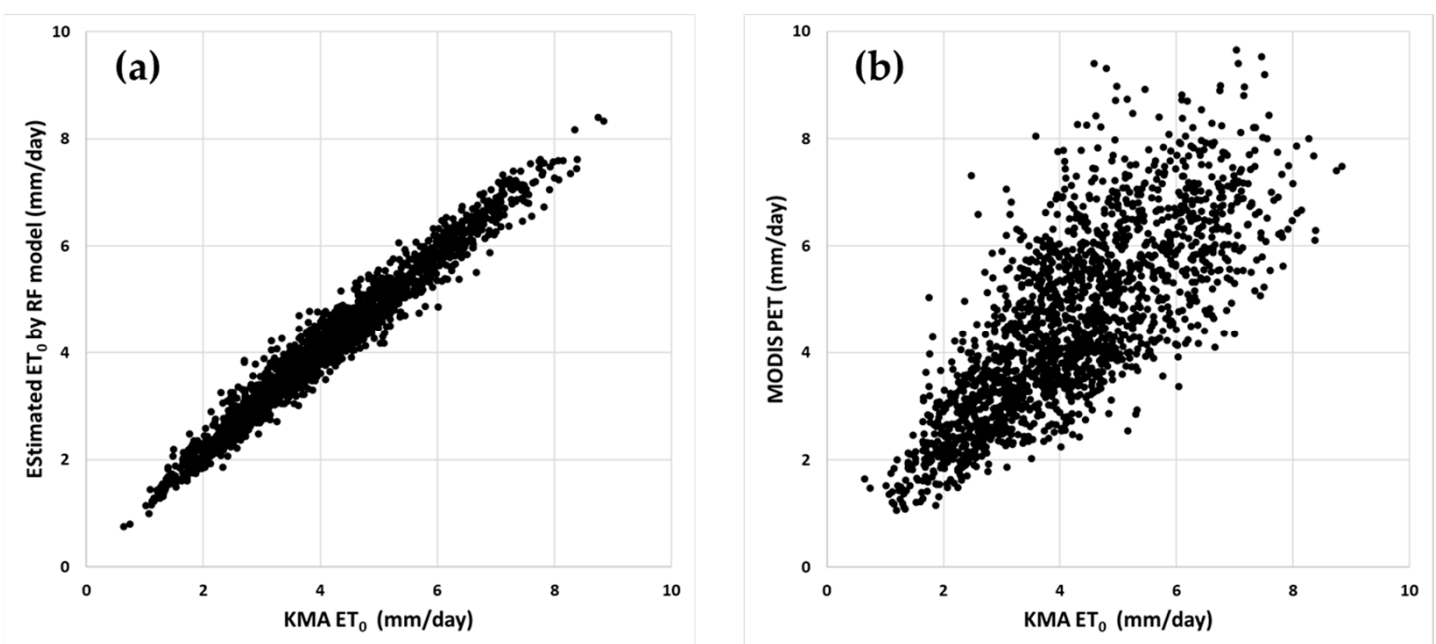

Figure 11. Scatterplots of the ML-based $\mathrm{ET}_{0}$ vs. KMA in situ data (a) and the MODIS PET vs. KMA in situ data (b) for the 8-day composite for croplands in South Korea for the 2013-2019 period.

\subsection{Agrometeorological Characteristics in Recent Years}

$\mathrm{ET}_{0}$ is a useful indicator to examine the impacts of the meteorological drought on vegetation conditions. Using the daily $\mathrm{ET}_{0}$ retrieved over the $500 \mathrm{~m}$ grid for the period between March and November of 2013-2019, a case study was analyzed to clarify the hydrological and meteorological characteristics of croplands in South Korea. We focused on the July and August of 2016-2018, during which heatwave and drought events occurred. From 12 July to 12 August, the land surface temperatures in 2016 and 2017 were typical (midday average, $32.4{ }^{\circ} \mathrm{C}$ and $32.2^{\circ} \mathrm{C}$, respectively). By contrast, the land surface temperatures in 2018 were remarkably high (midday average, $36.6^{\circ} \mathrm{C}$ ) (Figure 12). During that period, the average rainfall was 3.6 and $7.5 \mathrm{~mm} /$ day in 2016 and 2017, respectively, but only $0.8 \mathrm{~mm} /$ day in 2018. Because of the high temperatures and low rainfall, soil moisture decreased in 2018 (average, $29.9 \%$ ) compared to 2016 and 2017 (average, $35.3 \%$ and $36.9 \%$, respectively). The $\mathrm{ET}_{0}$ values were higher in 2018 (average, $6.0 \mathrm{~mm} /$ day) than in 2016 and 2017 (average, $4.7 \mathrm{~mm} /$ day and $5.0 \mathrm{~mm} /$ day, respectively). The combination of high land surface temperature and $\mathrm{ET}_{0}$ with low rainfall and soil moisture resulted in a reduced NDVI in 2018 (average, 0.72) than in 2016 and 2017 (average, 0.75 and 0.76, respectively). Figure 13 illustrates the NDVI from August 21 to 28 in 2017 and 2018, showing NDVI values with a different pattern. Insufficient rainfall leads to a deficit in the water supply to the land surface. When the higher $\mathrm{ET}_{0}$ is combined with severe meteorologically dry conditions due to a heatwave, it can cause excessive water loss from the land surface that exceeds the water supply from rainfall and irrigation. Therefore, considering the well-developed irrigation systems used in croplands in South Korea, a small degradation in the greenness of croplands can be regarded as indicating a critical deficit of water supply and excessive water consumption in the croplands. 

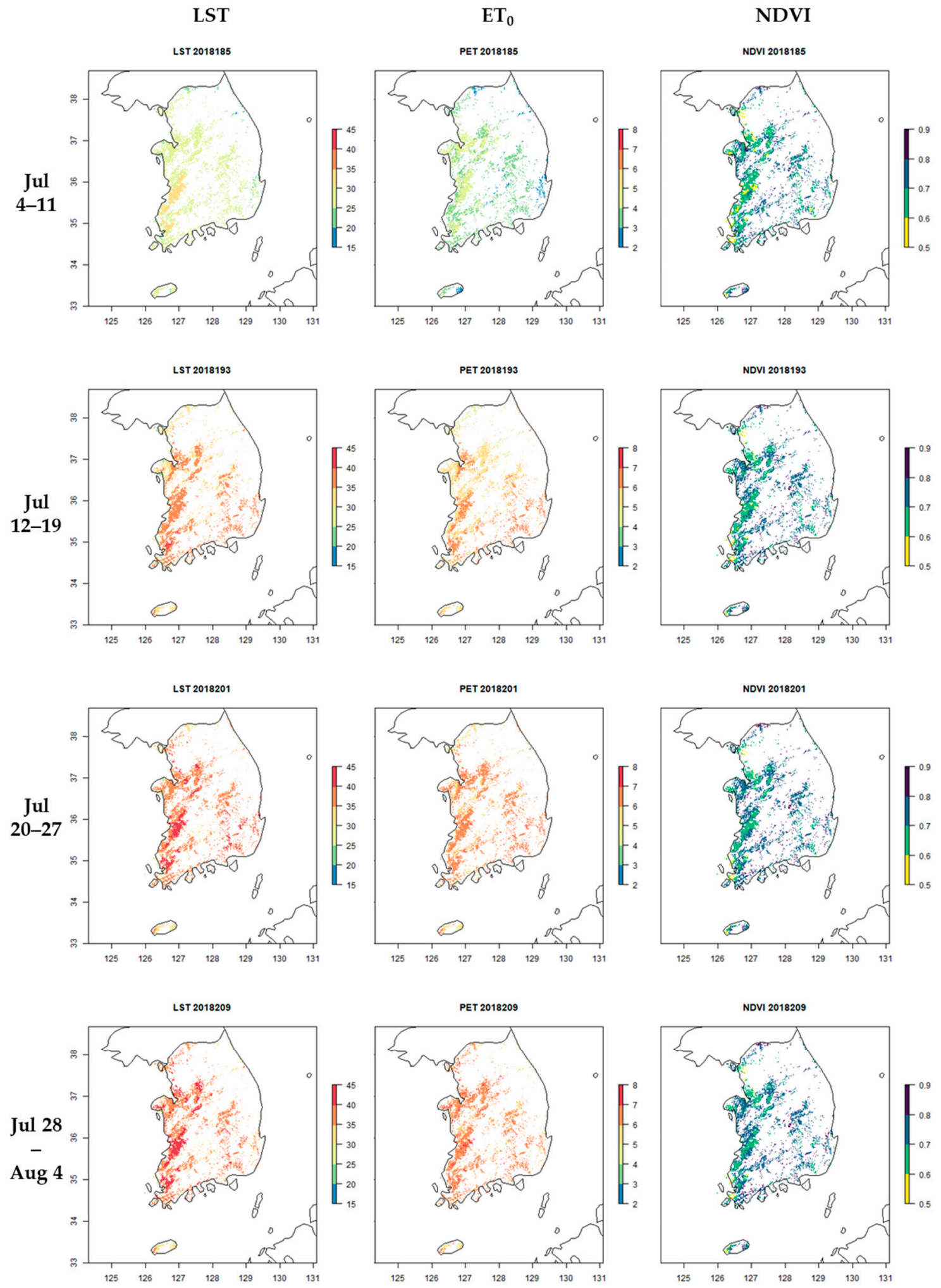

Figure 12. Cont. 

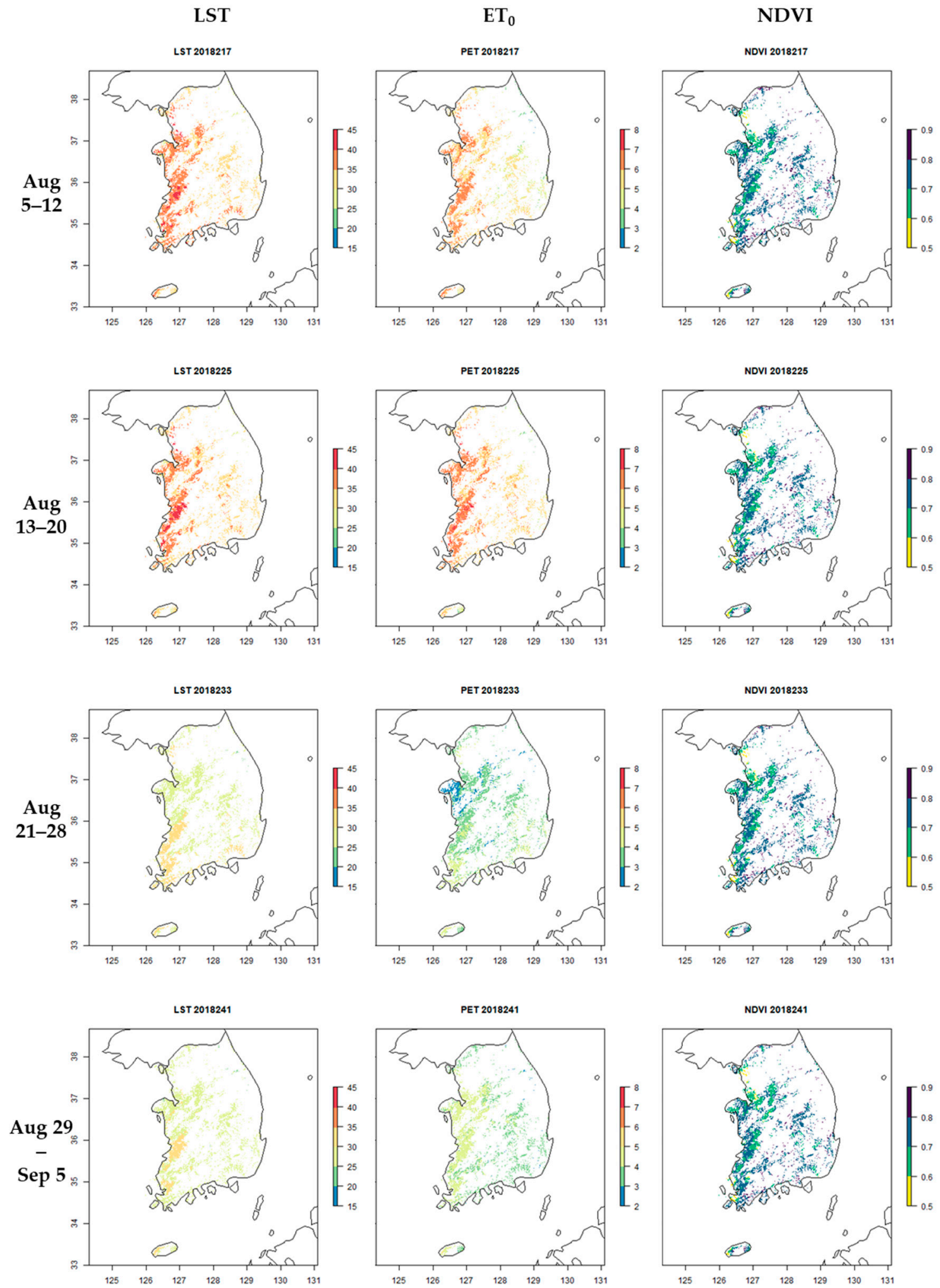

Figure 12. Maps of the land surface temperature (LST), reference evapotranspiration $\left(\mathrm{ET}_{0}\right)$, and normalized difference vegetation index (NDVI) for croplands in South Korea in July and August 2018. 
(a) NDVI 2017233

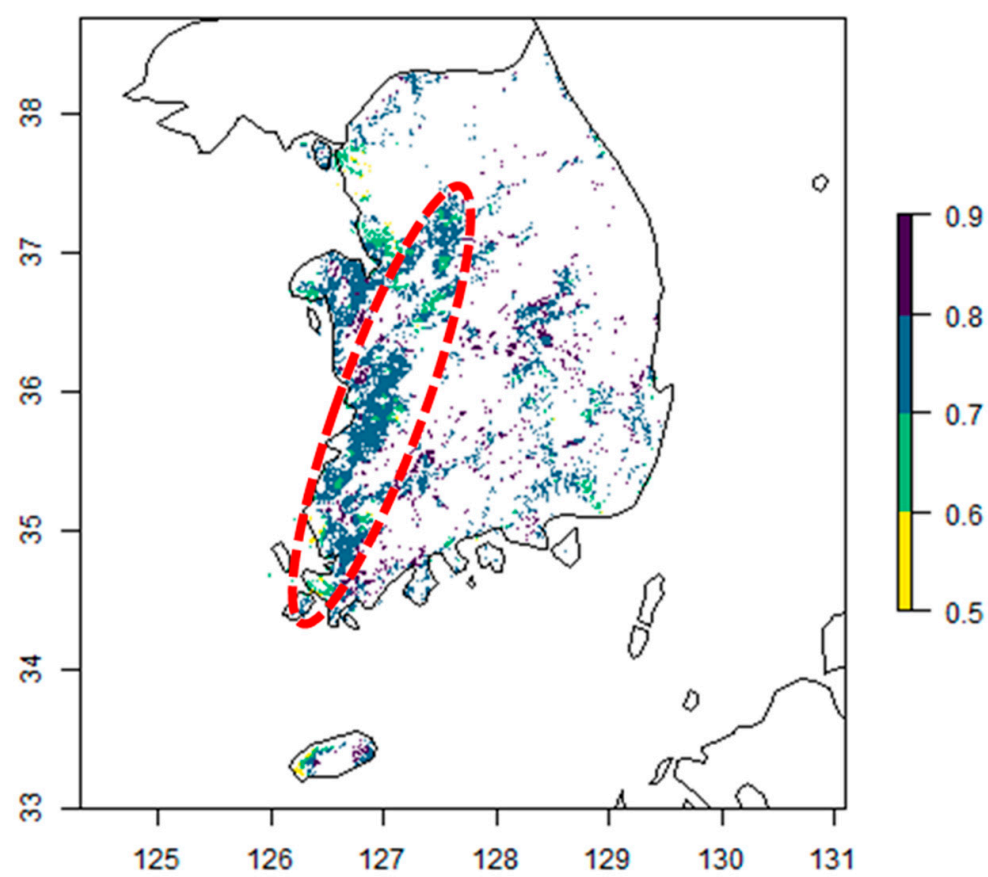

(b) NDVI 2018233

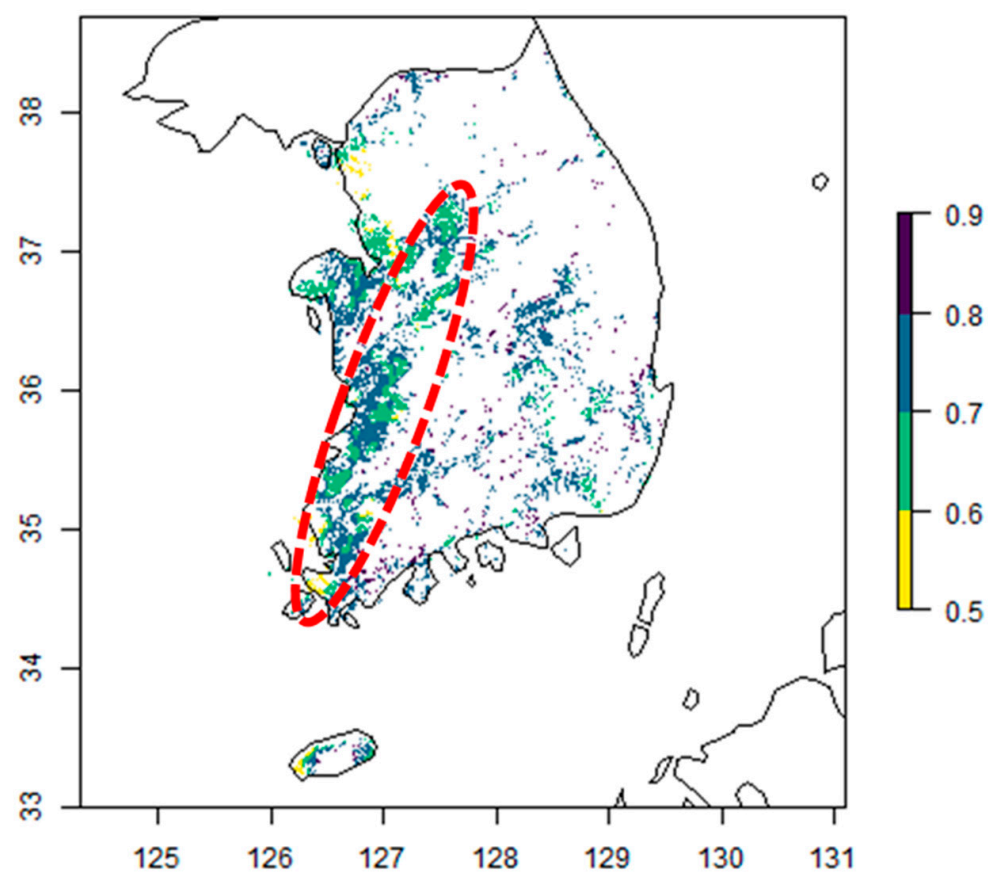

Figure 13. Maps of NDVI in the croplands in South Korea for August 21-28 of 2017 (a) and 2018 (b). The NDVI in 2018 was lower than in 2017 due to a heatwave, low rainfall, decreased soil moisture and increased $\mathrm{ET}_{0}$. The red dashed line denotes the major agricultural areas in South Korea. 


\section{Conclusions}

In this paper, we presented an ML-based retrieval of daily $\mathrm{ET}_{0}$ over a $500 \mathrm{~m}$ grid for croplands in South Korea using satellite images and NWP data. In a blind test for 2013-2019, the ML-based $\mathrm{ET}_{0}$ model produced highly accurate results, with an RMSE of $1.038 \mathrm{~mm} /$ day and the CC of 0.870 . The results of the blind test were stable irrespective of location, year, and month. This outcome is presumably because the input data of the ML-based $\mathrm{ET}_{0}$ model were suitably arranged spatially and temporally, and the optimization of the model was appropriate. In addition, the performance comparison with the operative MODIS PET product was conducted using 8-day composite data. Our ML model outperformed the MODIS product for croplands in South Korea because the ML model was locally optimized for South Korea, whereas MODIS PET was not. Our $\mathrm{ET}_{0}$ retrieval is expected to be an official product of the National Meteorological Satellite Center (NMSC) of South Korea since 2021 for the applications of agriculture, hydrology, and meteorology. Using the daily $\mathrm{ET}_{0}$ data produced over the $500 \mathrm{~m}$ grid, we conducted a case study to examine agrometeorological characteristics in July and August of 2016-2018. We found that low rainfall and high $\mathrm{ET}_{0}$ can damage the surface water balance when combined with a heatwave, resulting in reduced vegetation greenness. Through the experiments, the feasibility of the ML-based $\mathrm{ET}_{0}$ retrieval was validated, especially for local agrometeorological applications in regions with heterogeneous land surfaces, such as South Korea. However, a more detailed examination is required to test if the $500 \mathrm{~m}$ grids created from various spatial resolutions are statistically stable. The AI approaches using satellite images with NWP data can be a viable option for studying interactions between the land surface and atmosphere.

Author Contributions: Conceptualization, Y.L.; Data curation, N.K. and K.K.; Formal analysis, N.K. and K.K.; Methodology, Y.L.; Resources, S.L.; Writing-Original draft, N.K. and Y.L.; Writing-Review and editing, N.K., K.K., S.L., J.C., and Y.L. All authors have read and agreed to the published version of the manuscript.

Funding: This work was funded by the Korea Meteorological Administration Research and Development Program under the Grant KMI2018-05510.

Acknowledgments: The authors appreciate the National Meteorological Satellite Center for providing the in situ measurement data.

Conflicts of Interest: The authors declare no conflict of interest.

\section{References}

1. Hamon, W.R. Estimating potential evapotranspiration. J. Hydraul. Div. 1961, 87, 107-120.

2. Allen, R.G.; Pereira, L.S.; Raes, D.; Smith, M. Crop evapotranspiration-Guidelines for computing crop water requirements. In FAO Irrigation and Drainage Paper 56; FAO: Rome, Italy, 1998; Volume 300, p. D05109.

3. Sumner, D.M. Evapotranspiration from a cypress and pine forest subjected to natural fires, Volusia County, Florida, 1998-1999. In Water-Resources Investigations Report 2001-4245; USGS: Reston, VA, USA, 2001.

4. Thornthwaite, C.W. An approach toward a rational classification of climate. Geogr. Rev. 1948, 38, 55-94.

5. Wilson, K.; Goldstein, A.; Falge, E.; Aubinet, M.; Baldocchi, D.; Berbigier, P.; Bernhofer, C.; Ceulemans, R.; Dolman, H.; Field, C.; et al. Energy balance closure at FLUXNET sites. Agric. For. Meteorol. 2002, 13, $223-243$.

6. Sumner, D.M.; Jacobs, J.M. Utility of Penman-Monteith, Priestley-Taylor, reference evapotranspiration, and pan evaporation methods to estimate pasture evapotranspiration. J. Hydrol. 2005, 308, 81-104.

7. Kumar, A.; Bhatia, A.; Fagodiya, R.K.; Malyan, S.K.; Meena, B.L. Eddy covariance flux tower: A promising technique for greenhouse gases measurement. Adv. Plants Agric. Res. 2017, 7, 00263.

8. McMahon, T.A.; Peel, M.C.; Lowe, L.; Srikanthan, R.; McVicar, T.R. Estimating actual, potential, reference crop and pan evaporation using standard meteorological data: A pragmatic synthesis. Hydrol. Earth Syst. Sci. 2013, 17, 1331-1363.

9. Allen, R.G.; Tasumi, M.; Trezza, R. Satellite-based energy balance for mapping evapotranspiration with internalized calibration (METRIC)_Applications. J. Irrig. Drain. Eng. 2007, 133, 395-406.

10. Mu, Q.; Heinsch, F.A.; Zhao, M.; Running, S.W. Development of a global evapotranspiration algorithm based on MODIS and global meteorology data. Remote Sens. Environ. 2007, 111, 519-536. 
11. Jang, K.; Kang, S.; Kim, H.; Kwon, H. Evaluation of shortwave irradiance and evapotranspiration derived from moderate resolution imaging spectroradiometer (MODIS). Asia Pac. J. Atmos. Sci. 2009, 45, $233-246$.

12. Zhang, K.; Kimball, J.S.; Nemani, R.R.; Running, S.W. A continuous satellite-derived global record of land surface evapotranspiration from 1983 to 2006. Water Resour. Res. 2010, 46. [CrossRef]

13. Yuan, W.; Liu, S.; Yu, G.; Bonnefond, J.-M.; Chen, J.; Davis, K.; Desai, A.R.; Goldstein, A.H.; Gianelle, D.; Rossi, F.; et al. Global estimates of evapotranspiration and gross primary production based on MODIS and global meteorology data. Remote Sens. Environ. 2010, 114, 1416-1431.

14. Bruin, H.A.R.; Trigo, I.F.; Jitan, M.A.; Enku, N.; der Tol, C.; Gieske, A.S.M. Reference crop evapotranspiration derived from geo-stationary satellite imagery: A case study for the Fogera flood plain, NW-Ethiopia and the Jordan Valley, Jordan. Hydrol. Earth Syst. Sci. 2010, 14, 2219-2228.

15. Allen, R.; Irmak, A.; Trezza, R.; Hendrickx, J.M.; Bastiaanssen, W.; Kjaersgaard, J. Satellite-based ET estimation in agriculture using SEBAL and METRIC. Hydrol. Process. 2011, 25, 4011-4027.

16. Irmak, A.; Ratcliffe, I.; Ranade, P.; Hubbard, K.G.; Singh, R.K.; Kamble, B.; Kjaersgaard, J. Estimation of land surface evapotranspiration with a satellite remote sensing procedure. Great Plains Res. 2011, 73-88.

17. Mu, Q.; Zhao, M.; Running, S.W. Improvements to a MODIS global terrestrial evapotranspiration algorithm. Remote Sens. Environ. 2011, 115, 1781-1800.

18. Shoemaker, W.B.; Sumner, D.M. Alternate corrections for estimating actual wetland evapotranspiration from potential evapotranspiration. Wetlands 2006, 26, 528-543.

19. Anderson, M.C.; Norman, J.M.; Mecikalski, J.R.; Otkin, J.A.; Kustas, W.P. A climatological study of evapotranspiration and moisture stress across the continental United States based on thermal remote sensing: 2. Surface moisture climatology. J. Geophys. Res. Atmos. 2007, 112. [CrossRef]

20. Fisher, J.B.; Tu, K.P.; Baldocchi, D.D. Global estimates of the land-atmosphere water flux based on monthly AVHRR and ISLSCP-II data, validated at 16 FLUXNET sites. Remote Sens. Environ. 2008, 112, 901-919.

21. Kim, J.; Hogue, T.S. Evaluation of a MODIS-based potential evapotranspiration product at the point scale. J. Hydrometeorol. 2008, 9, 444-460.

22. Anderson, M.C.; Kustas, W.P.; Norman, J.M.; Hain, C.R.; Mecikalski, J.R.; Schultz, L.; González-Dugo, M.P.; Cammalleri, C.; d'Urso, G.; Pimstein, A.; et al. Mapping daily evapotranspiration at field to continental scales using geostationary and polar orbiting satellite imagery. Hydrol. Earth Syst. Sci. 2011, 15, 223-239.

23. Miralles, D.G.; Holmes, T.R.H.; De Jeu, R.A.M.; Gash, J.H.; Meesters, A.G.C.A.; Dolman, A.J. Global land-surface evaporation estimated from satellite-based observations. Hydrol. Earth Syst. Sci. 2011, 15, 453-469.

24. Yao, Y.; Liang, S.; Cheng, J.; Liu, S.; Fisher, J.B.; Zhang, X.; Jia, K.; Zhao, X.; Qin, Q.; Zhao, B.; et al. MODIS-driven estimation of terrestrial latent heat flux in China based on a modified Priestley-Taylor algorithm. Agric. For. Meteorol. 2013, 171, 187-202.

25. Yao, Y.; Liang, S.; Zhao, S.; Zhang, Y.; Qin, Q.; Cheng, J.; Jia, K.; Xie, X.; Zhang, N.; Liu, M. Validation and application of the modified satellite-based Priestley-Taylor algorithm for mapping terrestrial evapotranspiration. Remote Sens. 2014, 6, 880-904.

26. Yao, Y.; Liang, S.; Li, X.; Chen, J.; Wang, K.; Jia, K.; Cheng, J.; Jiang, B.; Fisher, J.B.; Mu, Q.; et al. A satellite-based hybrid algorithm to determine the Priestley-Taylor parameter for global terrestrial latent heat flux estimation across multiple biomes. Remote Sens. Environ. 2015, 165, 216-233.

27. Baik, J.; Choi, M. Evaluation of geostationary satellite (COMS) based Priestley-Taylor evapotranspiration. Agric. Water Manag. 2015, 159, 77-91.

28. Semmens, K.A.; Anderson, M.C.; Kustas, W.P.; Gao, F.; Alfieri, J.G.; McKee, L.; Prueger, J.H.; Hain, C.R.; Cammalleri, C.; Yang, Y.; et al. Monitoring daily evapotranspiration over two California vineyards using Landsat 8 in a multi-sensor data fusion approach. Remote Sens. Environ. 2016, 185, 155-170.

29. Jacobs, J.M.; Mergelsberg, S.L.; Lopera, A.F.; Myers, D.A. Evapotranspiration from a wet prairie wetland under drought conditions: Paynes prairie preserve, Florida, USA. Wetlands 2002, 22, 374-385.

30. Wang, K.; Liang, S. An improved method for estimating global evapotranspiration based on satellite determination of surface net radiation, vegetation index, temperature, and soil moisture. J. Hydrometeorol. 2008, 9, 712-727.

31. Wang, K.; Wang, P.; Li, Z.; Cribb, M.; Sparrow, M. A simple method to estimate actual evapotranspiration from a combination of net radiation, vegetation index, and temperature. J. Geophys. Res. Atmos. 2007, 112. [CrossRef] 
32. Papale, D.; Valentini, R. A new assessment of European forests carbon exchanges by eddy fluxes and artificial neural network spatialization. Glob. Chang. Biol. 2003, 9, 525-535.

33. Yeom, J.M.; Lee, C.S.; Park, S.J.; Ryu, J.H.; Kim, J.J.; Kim, H.C.; Han, K.S. Evapotranspiration in Korea estimated by application of a neural network to satellite images. Remote Sens. Lett. 2015, 6, 429-438.

34. Zhang, K.; Kimball, J.S.; Mu, Q.; Jones, L.A.; Goetz, S.J.; Running, S.W. Satellite based analysis of northern ET trends and associated changes in the regional water balance from 1983 to 2005. J. Hydrol. 2009, 379, 92-110.

35. Yang, F.; White, M.A.; Michaelis, A.R.; Ichii, K.; Hashimoto, H.; Votava, P.; Nemani, R.R. Prediction of continental-scale evapotranspiration by combining MODIS and AmeriFlux data through support vector machine. IEEE Trans. Geosci. Remote Sens. 2006, 44, 3452-3461.

36. Sulla-Menashe, D.; Friedl, M.A. User Guide to Collection 6 MODIS Land Cover (MCD12Q1 and MCD12C1) Product. Available online: https://lpdaac.usgs.gov/documents/101/MCD12_User_Guide_V6.pdf (accessed on 30 September 2020).

37. Huffman, G.J.; Adler, R.F.; Bolvin, D.T.; Nelkin, E.J. The TRMM multi-satellite precipitation analysis (TMPA). In Satellite Rainfall Applications for Surface Hydrology; Springer: Dordrecht, The Netherlands, 2010; pp. 3-22.

38. Zulkafli, Z.; Buytaert, W.; Onof, C.; Manz, B.; Tarnavsky, E.; Lavado, W.; Guyot, J.L. A comparative performance analysis of TRMM 3B42 (TMPA) versions 6 and 7 for hydrological applications over Andean-Amazon river basins. J. Hydrometeorol. 2014, 15, 581-592.

39. Breiman, L. Random forests. Mach. Learn. 2001, 45, 5-32.

40. Introduction to Boosted Trees. Available online: https://xgboost.readthedocs.io/en/latest/tutorials/model.html (accessed on 30 September 2020).

41. Belgiu, M.; Drăguţ, L. Random forest in remote sensing: A review of applications and future directions. ISPRS J. Photogramm. Remote Sens. 2016, 114, 24-31.

42. Kim, N.; Na, S.I.; Park, C.W.; Huh, M.; Oh, J.; Ha, K.J.; Cho, J.; Lee, Y.-W. An artificial intelligence approach to prediction of corn yields under extreme weather conditions using satellite and meteorological data. Appl. Sci. 2020, 10, 3785.

43. MOD16A2GF v006. Available online: https://pdaac.usgs.gov/products/mod16a2gfv006/ (accessed on 30 September 2020).

44. Batra, N.; Islam, S.; Venturini, V.; Gisht, G.; Jiang, L.E. 2006 Estimation and comparison of evapotranspiration from MODIS and AVHRR sensors for clear sky days over the Southern Great Plains. Remote Sens. Environ. 2006, 103, 1-15.

45. Wang, K.; Dickinson, R.E. A review of global terrestrial evapotranspiration: Observation, modeling, climatology, and climatic variability. Rev. Geophys. 2012, 50. [CrossRef]

46. Sun, S.; Chen, H.; Wang, G.; Li, J.; Mu, M.; Yan, G.; Xu, B.; Huang, J.; Wang, J.; Zhang, F.; et al. Shift in potential evapotranspiration and its implications for dryness/wetness over Southwest China. J. Geophys. Res. Atmos. 2016, 121, 9342-9355.

47. Jones, H.G. Plants and Microclimate: A Quantitative Approach to Environmental Plant Physiology, 2nd ed.; Cambridge University Press: Cambridge, UK, 1992.

48. Hmimina, G.; Dufrêne, E.; Pontailler, J.Y.; Delpierre, N.; Aubinet, M.; Caquet, B.; de Grandcourt, A.; Burban, B.; Flechard, C.; Granier, A.; et al. Evaluation of the potential of MODIS satellite data to predict vegetation phenology in different biomes: An investigation using ground-based NDVI measurements. Remote Sens. Environ. 2013, 132, 145-158.

49. Cai, Z.; Jonsson, P.; Jin, H.; Eklundh, L. Performance of smoothing methods for reconstructing NDVI time-series and estimating vegetation phenology from MODIS data. Remote Sens. 2017, 9, 1271.

Publisher's Note: MDPI stays neutral with regard to jurisdictional claims in published maps and institutional affiliations. 